Research Article

\title{
Experimental Evaluation of the Influences of Water on the Fracture Toughness of Mudstones with Bedding
}

\author{
Jianfeng Yang, ${ }^{1,2,3} \mathrm{Li} \mathrm{Li}\left(\mathbb{D},{ }^{4}\right.$ and Haojie Lian ${ }^{2,3}$ \\ ${ }^{1}$ School of Energy Engineering, Xi'an University of Science and Technology, Xi'an, Shaanxi 710054, China \\ ${ }^{2}$ Key Laboratory of In-Situ Property-Improving Mining of Ministry of Education, Taiyuan University of Technology, Taiyuan, \\ Shanxi 030024, China \\ ${ }^{3}$ College of Mining Engineering, Taiyuan University of Technology, Taiyuan, Shanxi 030024, China \\ ${ }^{4}$ Civil and Environmental Engineering, University of Waterloo, Ontario, Waterloo N2L3G1, Canada
}

Correspondence should be addressed to Li Li; 1463li@uwaterloo.ca

Received 11 October 2019; Accepted 4 December 2019; Published 20 December 2019

Academic Editor: Fernando Lusquiños

Copyright ( 2019 Jianfeng Yang et al. This is an open access article distributed under the Creative Commons Attribution License, which permits unrestricted use, distribution, and reproduction in any medium, provided the original work is properly cited.

\begin{abstract}
The effect of water on fracture toughness in various modes of mudstones was investigated using semicircular bend (SCB) specimens exposed to three-point bendings. Natural mudstone specimens are obtained using a special coring method and are then classified into three types (A, B, and C) corresponding to three directions/configurations of bedding planes (divider, arrester, and transverse). The results show that the Type A (divider configuration) specimens possess the largest fracture toughness value for all tested modes and same soaking time, whereas the Type C (transverse configuration) specimens have the smallest one. By increasing soaking time, the fracture toughness in all three modes decreases and the fracture mechanism changes from brittle failure to ductile failure. Among them, the Type $\mathrm{C}$ specimens have the highest degree of degradation for each soaking time period. Regarding the fracture modes, the degradation degree of $K_{\text {Ic }}$ is higher than that of $K_{\text {IIc }}$ for all three types of mudstone specimens. In addition, $K_{\mathrm{IIC}} / K_{\mathrm{Ic}}$ ratio increases when soaking time is extended. Furthermore, in the initial and short soaking time stages, the experimental $K_{\text {IIc }} / K_{\text {Ic }}$ results are consistent with theoretical findings from modified MTS criterion. However, after being soaked 300 minutes for three types of specimens, the test curves deviate from the theoretical curves. Analogously, the mixed-mode I/II ratio of $K_{\text {eff }}$ to $K_{\text {Ic }}$ is consistent with the theoretical values in the initial stage when the degree of damage is low. With soaking time increasing, the experimental curve is gradually deviated from the theoretical curve. When soaking time reaches 300 minutes, the deviation is substantial. And the test data for the Type-A specimens are observed to provide better agreements with theoretical predictions by modified MTS criterion than those for the other two types of specimens.
\end{abstract}

\section{Introduction}

Mudstones, a sort of sedimentary rocks containing clay minerals, are found extensively in a variety of engineering geological environments, such as mining, hydraulic fracturing, tunneling, blasting, and geological $\mathrm{CO}_{2}$ storage. Under these natural conditions, water is a significant factor that alters the physical and mechanical properties of argillaceous swelling rocks $[1,2]$. Some investigations of the effect of water on clay-bearing rocks have been conducted. For instance, Valès et al. [3] evaluated the influence of water content on anisotropic mechanical characteristics of claybearing shales, finding that the strength of these rocks and their cohesion and elastic modulus under uniaxial or triaxial stress states reduce with the increase of saturation degree. Pham et al. [4] and Erguler and Ulusay [5] drew out similar conclusions for mudstones. Gautam and Shakoor [6] observed that rocks containing higher amounts of clay slake more extensively and rapidly under natural climatic conditions and that the water content plays a key role in reducing the strength of clay-bearing rocks. Several experimental studies on wave velocities in clay-bearing rocks with rock-water interaction have been conducted [7].

Stress intensity factor (SIF) was defined by Irwin [8] based on linear elastic fracture mechanics (LEFM) to explain stress fields around crack tips. The critical value of SIF 
corresponding to crack propagation is referred to as the fracture toughness, which is a key mechanical parameter that characterizes rock resistance against crack propagation [9-12]. Experimental results have investigated the fracture toughness of synthetic rocks containing clay (which are regarded as isotropic materials) under the influence of water content $[13,14]$. Chen et al. [15] investigated the fracture toughness of anisotropic Hualien marble; their study showed that the angle of bedding influences pure mode II fracture toughness of rock samples. Wu et al. [16] obtained different values of pure mode I fracture toughness of coals and sandy mudstones for three types of specimens defined by the bedding direction of the rocks. To date, however, little has been reported on water influence on mudstones fracture toughness with bedding. The aim of the present paper is to address this shortcoming.

Multiple experimental methods and specimens have been developed to obtain the mixed-mode I/II fracture toughness of brittle materials, including a four-point shear specimen $[17,18]$, semicircular specimens under three-point bending (SCB) [19], compact tension-shear specimens [20], and cracked specimens of chevron notched Brazilian disk $[21,22]$. SCB is the best experimental configuration among these specimens and methods for evaluating modes I and II and mixed-mode I/II fracture toughness of rock materials owing to its simple machining process, ease of testing by simple application of three-point compressive loadings, and the minimal use of rock materials. Since Chong et al. [23-25] advocated the use of SCB to evaluate different modes of fracture toughness in rock, Lim et al. [26] performed the simulation of the SIFs of SCB specimens in different geometries of specimens and showed that SCB technique could be applied to a range of mixed-mode I/II configurations. A test standard suggested by International Society for Rock Mechanics (ISRM) for mode I static fracture toughness of rock employing SCB specimen has been presented [19]. Ayatollahi et al. [27, 28] introduced the fracture parameter $\mathrm{T}$-stress to calculate fracture toughness in SCB specimens using finite element method, and modified maximum tangential stress (MMTS) criterion has been used calculate mode II and I/II mixed-mode fracture toughness in terms of mode I fracture toughness. This test uses a specific coring method to acquire natural mudstone cores for machining SCB specimens. The mudstone SCB specimens are classified into three types based on orientation of the bedding plane and used to conduct experimental research on the influence of water on the pure modes I and II and mixed-mode I/II fracture toughness of mudstones. Furthermore, based on the MMTS criterion, a comparison is performed between test results and theoretical values.

\section{Experimental Methods and Progress}

2.1. SCB Specimens under Three-Point Bendings. Chong and Kuruppu [23] suggested using an SCB specimen exposed to three-point bending to perform all modes of fracture toughness tests on rock samples, including pure modes I and II and mix mode I/II. Figure 1 shows a semicircular disc specimen with the radius of $R$ and a radial edge crack with the length of $\alpha$ previously prepared from the center. Fracture toughness tests are conducted using a vertical compressive force $(P)$ along specimen axis on a three-point-bending machine. $K_{\mathrm{I}}$ and $K_{\mathrm{II}}$ denoted SIFs of modes I and II for SCB specimen, respectively, and are written as follows [29]:

$$
\begin{aligned}
K_{\mathrm{I}} & =\frac{P \sqrt{\pi \alpha}}{2 R B} Y_{\mathrm{I}}\left(\frac{\alpha}{R}, \frac{S}{R}, \beta\right), \\
K_{\mathrm{II}} & =\frac{P \sqrt{\pi \alpha}}{2 R B} Y_{\mathrm{II}}\left(\frac{\alpha}{R}, \frac{S}{R}, \beta\right),
\end{aligned}
$$

where $P$ is compressive force. Crack propagation begins when compressive force $P$ reaches peak load, $P_{\mathrm{cr}}$. Fracture toughness $K_{\text {Ic }}$ and $K_{\text {IIc }}$ values are obtained by equations (1) and (2). Also, $B$ is specimen thickness, $\beta$ is the departure angle of preexisting crack from vertical direction, $\alpha / R$ is the ratio of crack length to semicircular radius, and $S / R$ is the ratio of half distance between two supporting cylindrical rollers to radius. $Y_{\mathrm{I}}$ and $Y_{\mathrm{II}}$ are geometric factors of modes I and II, respectively, which are functions of $S / R, \alpha / R$, and $\beta$ geometric parameters. Test methods for various fracture toughness modes are achieved by the variation of the values of these geometric parameters. For instance, at $\beta=0$, pure mode I loading is under SCB specimen. Ayatollahi and Aliha [29] used finite element method to determine $Y_{\mathrm{I}}$ and $Y_{\mathrm{II}}$ values for pure modes I and II loading under the conditions of different geometries and determined the value of $\beta$ of pure mode II loadings for various $S / R$ and $\alpha / R$ values.

2.2. Materials and Sample Preparation. Mudstone samples used in this work were obtained from 150-200 m depth of Xiegou Coal Mine in Lvliang City, Shanxi Province, China. The mineral component of the rock was determined semiquantitatively using X-ray diffraction (XRD), and Figure 2 shows a typical XRD pattern. Clay content in the specimens is $34 \%$, including kaolinite and illite. The rest is composed predominantly of silicon dioxide and potash feldspar. It is almost impossible to obtain cylinder mudstone specimens by traditional drilling cores due to limitations of the brittle bedding architecture, the likelihood of mechanical damage, and the influence of the water. Several investigators have used synthetic mudstone instead of natural mudstone for test specimen preparation $[30,31]$. However, in this test, a special coring method was used to acquire natural mudstone specimens in different directions of stratification. A $1.5 \mathrm{~mm}$ carborundum wire saw in a numerical control machine with lubricating oil coolant was used to collect core samples. Sedimentary rocks generally have layered structures and are considered to have transversely isotropic properties. For mudstone in particular, the influence of water on clay-bearing sedimentary rock specimens increases the degree of anisotropy. The ISRM has suggested that the sedimentary rock SCB specimens whose notches are oriented along three mutually perpendicular directions defined as arrester, short transverse, and divider directions should be tested to determine mode I fracture toughness [19].

This test defined three types of the SCB specimens designated as Types A (divider), B (arrester), and C 


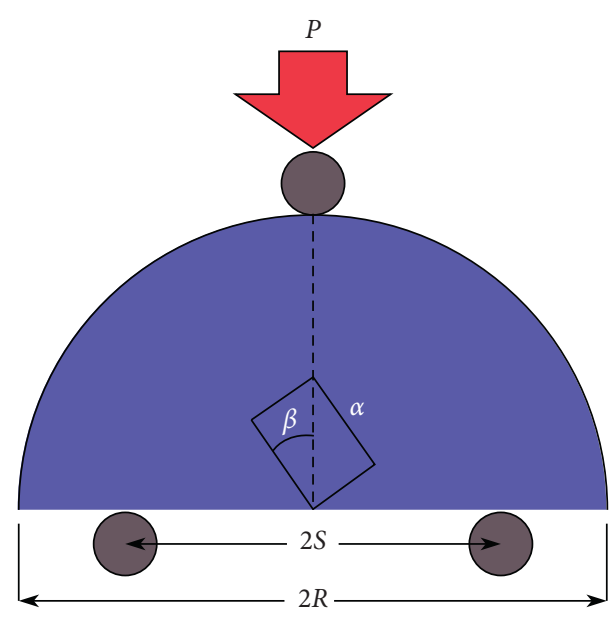

Figure 1: The SCB specimen.

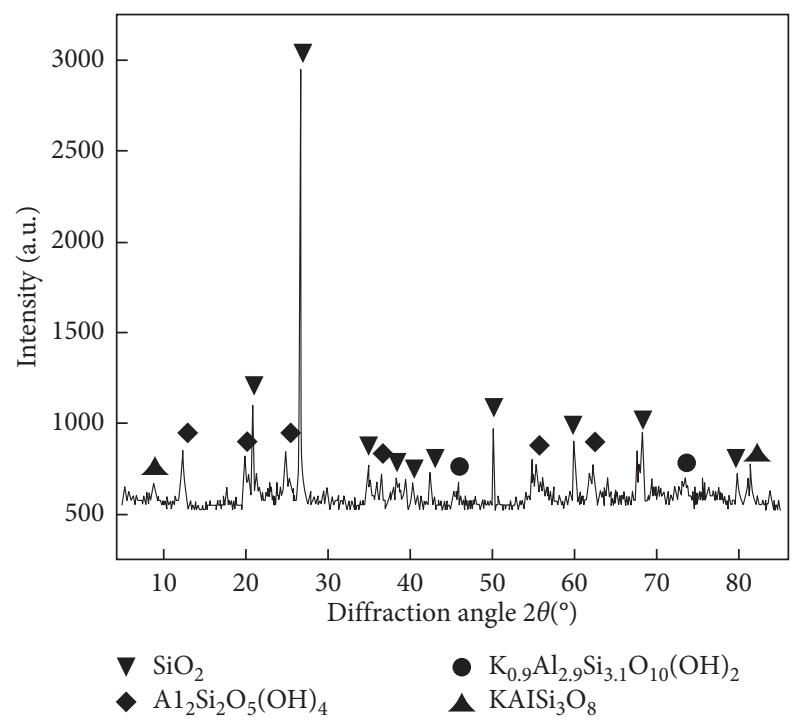

FIGURE 2: XRD spectrum of the mudstone.

(transverse) corresponding to three bedding directions (see Figure 3). Consequently, the semicircular specimens were cut into pieces with radius $25 \mathrm{~mm}(R=25 \mathrm{~mm})$ and thickness $20 \mathrm{~mm}(B=20 \mathrm{~mm})$. On this basis, a straight notch of each semicircle was previously prepared with a $0.5 \mathrm{~mm}$ diamondimpregnated fine wire saw. $\alpha / R$ ratio value was 0.35 , and the values of $\beta$ were $0^{\circ}, 5^{\circ}, 15^{\circ}, 30^{\circ}, 45^{\circ}$, and $54^{\circ}$. Figure 4 shows the geometrical characteristics of the SCB specimens (Types $\mathrm{A}, \mathrm{B}$, and $\mathrm{C}$ ).

All the samples were placed in a drying oven for $24 \mathrm{~h}$ at $105^{\circ} \mathrm{C}$ and were then cooled to room temperature. To investigate early effect on mudstone, the SCB specimens were submerged in water for different duration. For characteristics and the size of this mudstone specimen, the specimens were placed in water for $0,50,100,200$, and 300 minutes to impose different degrees of damage. Here, $S / R$ ratio was 0.5 and displacement loading rate was set at $0.02 \mathrm{~mm} / \mathrm{min}$ to determine static fracture toughness [32]. Geometric factors $Y_{\mathrm{I}}$ and $Y_{\mathrm{II}}$ of SCB specimens at $a / R$ and $S / R$ values of 0.35 and 0.5 , respectively, were calculated by finite element method under pure mode II and mixed-mode I/II loadings [33]. Pure mode I fracture toughness was calculated under $Y_{\mathrm{I}} \neq 0$ and $Y_{\mathrm{II}}=0$ conditions for $\beta=0^{\circ}$. Pure mode II fracture toughness was obtained under $Y_{\mathrm{I}}=0$ and $Y_{\mathrm{II}} \neq 0$ conditions for $\beta=54^{\circ}$ (Ayatollahi and Aliha [33]). Finally, mixed-mode I/II fracture toughness was obtained under $Y_{\mathrm{I}} \neq 0$ and $Y_{\mathrm{II}} \neq 0$ conditions for $\beta \neq 0^{\circ}$ and $\beta \neq 54^{\circ}\left(\beta=5^{\circ}, 15^{\circ}, 30^{\circ}\right.$, and $45^{\circ}$ were tested here). The parameter values of $Y_{\mathrm{I}}$ and $Y_{\mathrm{II}}$ are listed in Table $1 . K_{\mathrm{I}}$ and $K_{\mathrm{II}}$ of the mudstone are calculated by equations (1) and (2). In this work, at least three specimens were tested for each condition. In total, approximately 300 mudstone SCB specimens were tested.

\section{Results and Discussion}

3.1. Pure Mode I Fracture Toughness of Mudstones. Tables 2-4 summarize mode I fracture toughness of three mudstone specimens with various soaking durations. For the initial specimens, the average mode I fracture toughness was $0.85 \mathrm{MPa} \cdot \mathrm{m}^{0.5}, 0.82 \mathrm{MPa} \cdot \mathrm{m}^{0.5}$, and $0.73 \mathrm{MPa} \cdot \mathrm{m}^{0.5}$. For each soaking time, average mode I fracture toughness of different mudstone specimens also showed differences. Load-displacement curves of three types of mudstone samples after they were soaked in water for the pure mode I loading condition are shown in Figure 5. Mudstone peak load after being submerged in water is smaller than the peak load of intact mudstone, and peak load is decreased with increasing soaking time.

The load-displacement curve is concave in initial compaction loading stage because of microcracks inside rock closing exposed to external forces. In elastic compaction stage, the load shows an approximately linear relationship with the displacement up to the peak load. Increasing submersion time widens compaction stage and load-displacement curve slope in elastic stage is sharply decreased. This change is more apparent in Type B specimens, where the direction of loading is perpendicular to bedding plane, than in the other two types. Furthermore, brittle fracture occurs in the undamaged and low-damage mudstone specimens. However, at a soaking time of 300 minutes, 200 minutes, and 200 minutes for Type A, B, and C specimens, respectively, mudstone specimens become more softened and ductile. When the soaking time is far more than 300 minutes, the three types of these mudstone samples will disintegrate. Water has a prominent effect on mudstone failure characteristics, which transforms from being brittle to being ductile. In addition, the load-displacement curves of three different specimens in mode II or mixed-mode I/II loadings variation tendencies are approximately consistent with that of the mode I loading.

3.2. The Effect of Water on the Fracture Toughness of the Mudstones. Several pure modes I and II and mixed-mode I/ II fracture toughness tests were performed on mudstone for various soaking times with the three types of SCB specimens. After soaking for 50, 100, 200, and 300 minutes in water, the average gravimetric water content of the specimens was 

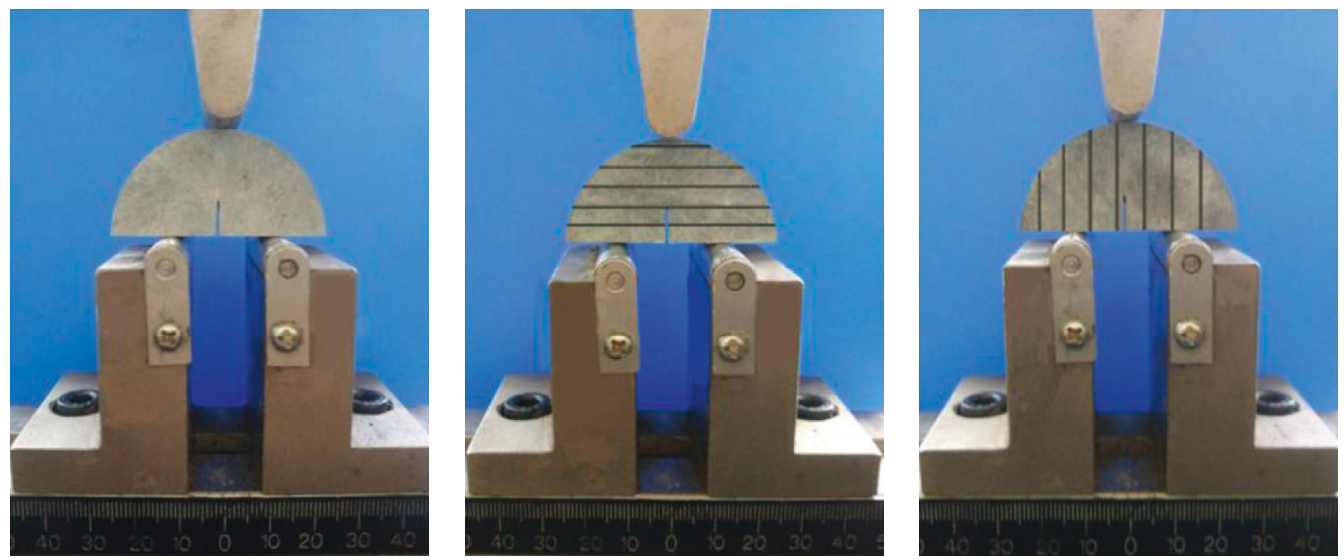

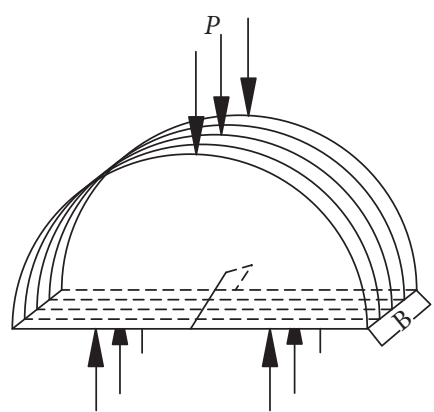

(a)

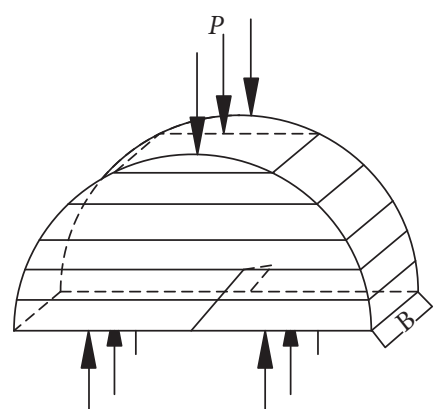

(b)

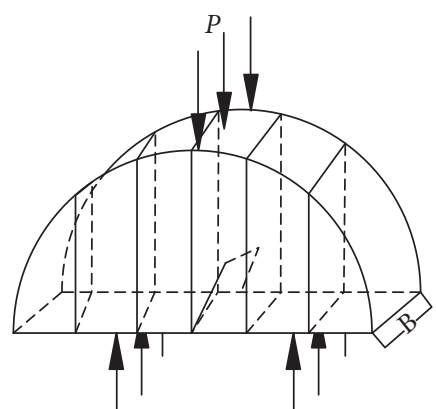

(c)

Figure 3: Three types of SCB specimens. (a) Type A (divider). (b) Type B (arrester). (c) Type C (transverse).

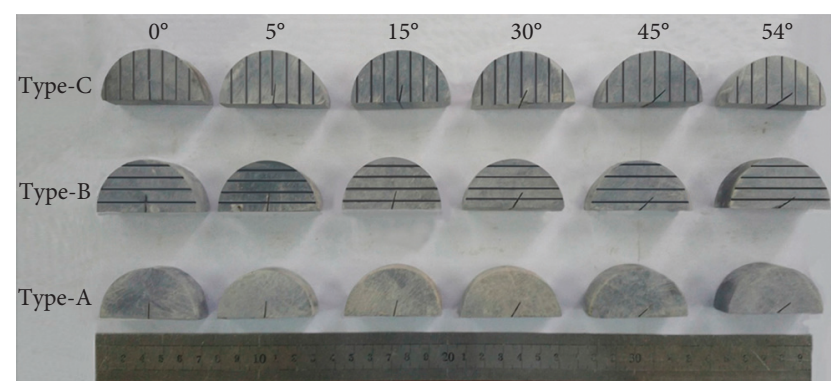

FIGURE 4: Three types of SCB specimens for different crack angles.

TABle 1: Fracture parameters $\left(Y_{\mathrm{I}}, Y_{\mathrm{II}}, T^{*}\right)$ for the SCB specimens with $(\alpha / R=0.35$ and $S / R=0.50)$ and for various crack inclination angles (according to Ayatollahi and Aliha [34]).

\begin{tabular}{lcccc}
\hline$\beta\left(^{\circ}\right)$ & $Y_{\mathrm{I}}$ & $Y_{\text {II }}$ & $T^{*}$ & $M^{e}$ \\
\hline 0 & 2.787 & 0 & -0.6972 & 1 \\
5 & 2.748 & 0.249 & -0.5918 & 0.9425 \\
15 & 2.397 & 0.671 & 0.0142 & 0.8262 \\
30 & 1.461 & 0.978 & 1.4875 & 0.6245 \\
45 & 0.518 & 0.871 & 2.7143 & 0.3416 \\
54 & 0 & 0.659 & 3.0830 & 0 \\
\hline
\end{tabular}

$1.8 \%, 3.3 \%$, $5.9 \%$, and $7.8 \%$, respectively. After a short soaking time, the interaction of rock and water is not strong, and water content is lower. With increasing soaking time, the water-rock interaction becomes stronger, and fracture toughness of the mudstone degrades rapidly. Fracture toughness degradation degree is obtained by

$$
D_{i t}=\frac{K_{i 0}-K_{i t}}{K_{i 0}} \times 100 \%, \quad i=\mathrm{I}, \mathrm{II} ; t=0,50,100,200,300 \text {, }
$$

where $K_{i t}=$ different mode fracture toughness of mudstone after $t$ minutes of soaking in the water. Deterioration trends of three specimens are equal. Nevertheless, the degree of degradation of the Type $C$ specimens is higher than that of the other types for each time point. During contact with water, because of the presence of clay minerals such as kaolinite and illite particles that exhibit strong hydrophilicity, a water molecular layer is formed and continuously extended as water penetrates between these particles. In addition, the water molecules enter illite; consequently, the clay mineral crystal cell layers cause the spacing to increase, and the binding force is reduced between the crystals. The chemical reaction process is as follows [35]:

$$
\begin{aligned}
\mathrm{K}_{0.9} \mathrm{Al}_{2.9} \mathrm{Si}_{3.1} \mathrm{O}_{10}(\mathrm{OH})_{2}+n \mathrm{H}_{2} \mathrm{O} \longrightarrow & \mathrm{K}_{0.9} \mathrm{Al}_{2.9} \mathrm{Si}_{3.1} \mathrm{O}_{10}(\mathrm{OH}) \\
& \cdot n \mathrm{H}_{2} \mathrm{O}
\end{aligned}
$$

The first mechanism causes external expansion of the clay minerals, and the second causes internal expansion. Nonuniform stress is produced due to uneven expansion within the rock. Furthermore, the coarse grains and their intermediate cementation become softened and dissolve, 
TABle 2: Mode I fracture toughness of Type A mudstone specimens for different soaking times.

\begin{tabular}{|c|c|c|c|c|c|}
\hline \multirow[t]{2}{*}{ Specimen number } & \multirow[t]{2}{*}{ Soaking time $t$ (minutes) } & \multirow[t]{2}{*}{ Peak load $P_{\text {cr }}(\mathrm{N})$} & \multicolumn{2}{|c|}{$\begin{array}{l}\text { Mode I fracture toughness } \\
K_{\mathrm{Ic}}\left(\mathrm{MPa} \cdot \mathrm{m}^{0.5}\right)\end{array}$} & \multirow[t]{2}{*}{ Degradation degree $D_{i t}(\%)$} \\
\hline & & & Test value & Average value & \\
\hline AI0-1 & 0 & $1839.5 \pm 0.01$ & 0.850 & & \\
\hline $\mathrm{AIO}-2$ & 0 & $1781.1 \pm 0.01$ & 0.823 & 0.850 & 0 \\
\hline $\mathrm{AIO}-3$ & 0 & $1897.9 \pm 0.01$ & 0.877 & & \\
\hline AI50-1 & 50 & $1694.5 \pm 0.01$ & 0.783 & & \\
\hline AI50-2 & 50 & $1649.1 \pm 0.01$ & 0.762 & 0.780 & -8.24 \\
\hline AI50-3 & 50 & $1720.5 \pm 0.01$ & 0.795 & & \\
\hline AI100-1 & 100 & $1544.5 \pm 0.01$ & 0.714 & & \\
\hline AI100-2 & 100 & $1567.9 \pm 0.01$ & 0.724 & 0.690 & -18.82 \\
\hline AI100-3 & 100 & $1367.3 \pm 0.01$ & 0.632 & & \\
\hline AI200-1 & 200 & $1304.8 \pm 0.01$ & 0.603 & & \\
\hline AI200-2 & 200 & $1250.7 \pm 0.01$ & 0.578 & 0.605 & -28.82 \\
\hline AI200-3 & 200 & $1372.5 \pm 0.01$ & 0.634 & & \\
\hline AI300-1 & 300 & $1133.4 \pm 0.01$ & 0.524 & & \\
\hline AI300-2 & 300 & $1218.0 \pm 0.01$ & 0.563 & 0.535 & -37.06 \\
\hline AI300-3 & 300 & $1122.1 \pm 0.01$ & 0.518 & & \\
\hline
\end{tabular}

TABLE 3: Mode I fracture toughness of Type B mudstone specimens for different soaking times.

\begin{tabular}{|c|c|c|c|c|c|}
\hline \multirow[t]{2}{*}{ Specimen number } & \multirow[t]{2}{*}{ Soaking time $t$ (minutes) } & \multirow[t]{2}{*}{ Peak load $P_{\mathrm{cr}}(\mathrm{N})$} & \multicolumn{2}{|c|}{$\begin{array}{l}\text { Mode I fracture toughness } \\
K_{\mathrm{Ic}}\left(\mathrm{MPa} \mathrm{m} \mathrm{m}^{0.5}\right)\end{array}$} & \multirow[t]{2}{*}{ Degradation degree $D_{i t}(\%)$} \\
\hline & & & Test value & Average value & \\
\hline BI0-1 & 0 & $1768.1 \pm 0.01$ & 0.817 & & \\
\hline $\mathrm{BI} 0-2$ & 0 & $1839.5 \pm 0.01$ & 0.850 & 0.820 & 0 \\
\hline $\mathrm{BI} 0-3$ & 0 & $1716.2 \pm 0.01$ & 0.793 & & \\
\hline BI50-1 & 50 & $1603.6 \pm 0.01$ & 0.741 & & \\
\hline BI50-2 & 50 & $1508.4 \pm 0.01$ & 0.697 & 0.745 & -9.15 \\
\hline BI50-3 & 50 & $1724.8 \pm 0.01$ & 0.797 & & \\
\hline BI100-1 & 100 & $1325.9 \pm 0.01$ & 0.615 & & \\
\hline BI100-2 & 100 & $1373.4 \pm 0.01$ & 0.640 & 0.623 & -24.02 \\
\hline BI100-3 & 100 & $1318.4 \pm 0.01$ & 0.614 & & \\
\hline BI200-1 & 200 & $1157.8 \pm 0.01$ & 0.539 & & \\
\hline BI200-2 & 200 & $1218.4 \pm 0.01$ & 0.564 & 0.548 & -33.17 \\
\hline BI200-3 & 200 & $1152.1 \pm 0.01$ & 0.541 & & \\
\hline BI300-1 & 300 & $1046.5 \pm 0.01$ & 0.443 & & \\
\hline $\mathrm{BI} 300-2$ & 300 & $1141.2 \pm 0.01$ & 0.480 & 0.452 & -44.88 \\
\hline BI300-3 & 300 & $1026.3 \pm 0.01$ & 0.433 & & \\
\hline
\end{tabular}

TABle 4: Mode I fracture toughness of the Type C mudstone specimens for different soaking times.

\begin{tabular}{|c|c|c|c|c|c|}
\hline \multirow[t]{2}{*}{ Specimen number } & \multirow[t]{2}{*}{ Soaking time $t$ (minutes) } & \multirow[t]{2}{*}{ Peak load $P_{\text {cr }}(\mathrm{N})$} & \multicolumn{2}{|c|}{$\begin{array}{l}\text { Mode I fracture toughness } \\
K_{\mathrm{Ic}}\left(\mathrm{MPa} \mathrm{m}{ }^{0.5}\right)\end{array}$} & \multirow[t]{2}{*}{ Degradation degree $D_{i t}(\%)$} \\
\hline & & & Test value & Average value & \\
\hline $\mathrm{CI} 0-1$ & 0 & $1711.8 \pm 0.01$ & 0.791 & & \\
\hline $\mathrm{CI} 0-2$ & 0 & $1487.6 \pm 0.01$ & 0.687 & 0.730 & 0 \\
\hline $\mathrm{CI} 0-3$ & 0 & $1540.2 \pm 0.01$ & 0.712 & & \\
\hline CI50-1 & 50 & $1329.2 \pm 0.01$ & 0.614 & & \\
\hline CI50-2 & 50 & $1289.0 \pm 0.01$ & 0.596 & 0.640 & -13.33 \\
\hline CI50-3 & 50 & $1537.0 \pm 0.01$ & 0.710 & & \\
\hline CI100-1 & 100 & $1077.5 \pm 0.01$ & 0.498 & & \\
\hline CI100-2 & 100 & $1187.6 \pm 0.01$ & 0.548 & 0.508 & -30.41 \\
\hline CI100-3 & 100 & $1033.6 \pm 0.01$ & 0.478 & & \\
\hline CI200-1 & 200 & $749.0 \pm 0.01$ & 0.346 & & \\
\hline CI200-2 & 200 & $670.0 \pm 0.01$ & 0.310 & 0.315 & -56.85 \\
\hline CI200-3 & 200 & $625.9 \pm 0.01$ & 0.289 & & \\
\hline CI300-1 & 300 & $474.8 \pm 0.01$ & 0.219 & & \\
\hline CI300-2 & 300 & $501.2 \pm 0.01$ & 0.232 & 0.214 & -70.68 \\
\hline CI300-3 & 300 & $413.3 \pm 0.01$ & 0.191 & & \\
\hline
\end{tabular}




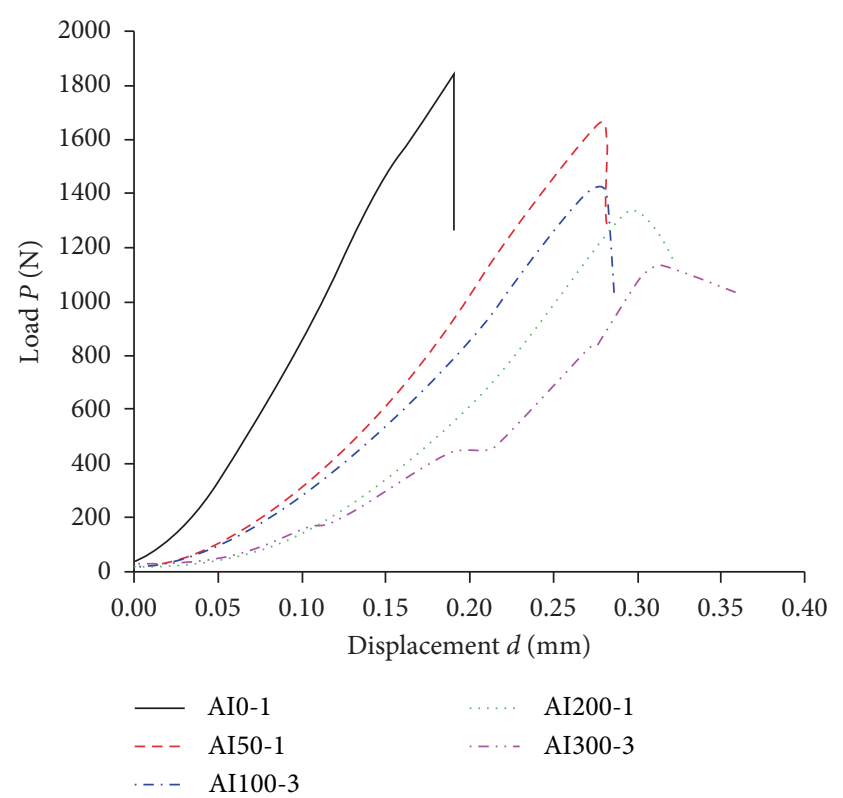

(a)

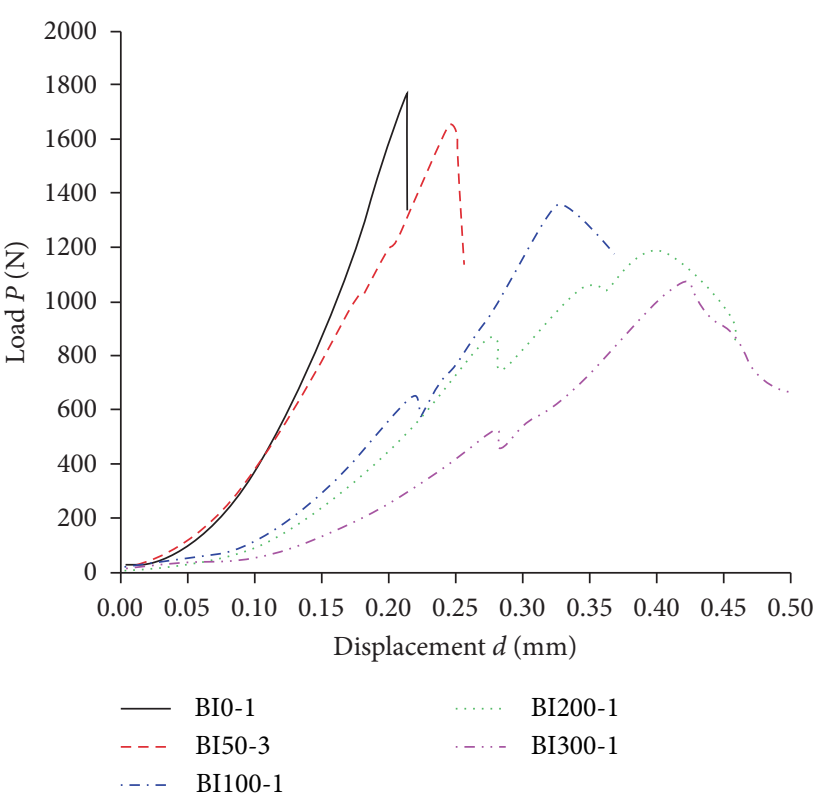

(b)

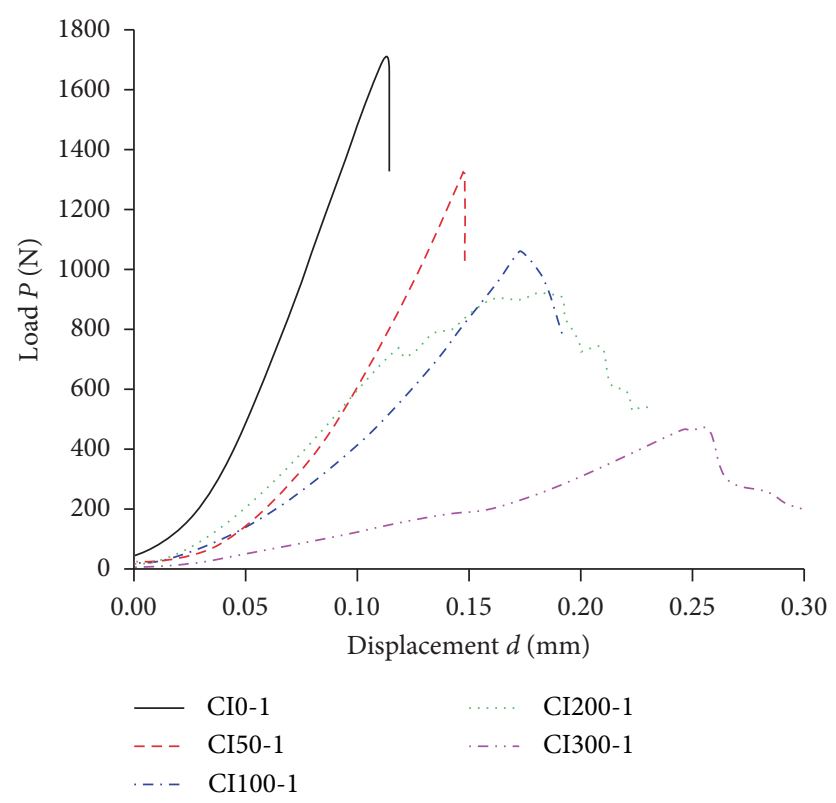

(c)

FIgURE 5: Load-displacement curves of three mudstone specimens after various soaking times. (a) Type A. (b) Type B. (c) Type C.

increasing internal microcracks and expansion. With increasing soaking time, the fracture toughness of mudstone gradually decreases.

3.3. The Pure Mode II Fracture Toughness of Mudstones. Pure mode II fracture toughness values of three different types of initial mudstone specimens are $0.272 \mathrm{MPa} \cdot \mathrm{m}^{0.5}$, $0.269 \mathrm{MPa} \cdot \mathrm{m}^{0.5}$, and $0.255 \mathrm{MPa} \cdot \mathrm{m}^{0.5}$, as shown in Tables $5-7$. By increasing soaking time, mode I fracture toughness degradation degree is larger than the corresponding value for mode II. It demonstrates that the water sensitivity of pure mode II fracture toughness is less than that of mode I. When the mudstone interacts with water, the tensile (mode I) microcracks tend to appear around the crystal in the mudstone specimens [36]. It causes the mode I fracture toughness of mudstone specimens easier to reduce after soaking in water.

Along with experimental methods, many theoretical criteria such as maximum energy release rate [37], minimum strain energy density [38], and maximum tangential stress (MTS) [39] have been developed for fracture behavior prediction in mixed modes. Among the three criteria, the MTS criterion is the most prominent and widely used because it is convenient and quantifiable. The traditional MTS criterion states that fracture happens when tangential stress 
TABLe 5: Mode II fracture toughness of Type A mudstone specimens for different soaking times.

\begin{tabular}{|c|c|c|c|c|c|}
\hline \multirow[t]{2}{*}{ Specimen number } & \multirow[t]{2}{*}{ Soaking time $t$ (minutes) } & \multirow[t]{2}{*}{ Peak load $P_{\text {cr }}(\mathrm{N})$} & \multicolumn{2}{|c|}{$\begin{array}{l}\text { Mode II fracture toughness } \\
K_{\text {IIc }}\left(\mathrm{MPa} \mathrm{m}{ }^{0.5}\right)\end{array}$} & \multirow[t]{2}{*}{ Degradation degree $D_{i t}(\%)$} \\
\hline & & & Test value & Average value & \\
\hline AII0-1 & 0 & $1976.9 \pm 0.01$ & 0.286 & & \\
\hline AII0-2 & 0 & $2122.5 \pm 0.01$ & 0.271 & 0.272 & 0 \\
\hline AII0-3 & 0 & $2122.9 \pm 0.01$ & 0.259 & & \\
\hline AII50-1 & 50 & $2554.5 \pm 0.01$ & 0.278 & & \\
\hline AII50-2 & 50 & $2401.6 \pm 0.01$ & 0.265 & 0.265 & -2.57 \\
\hline AII50-3 & 50 & $2301.3 \pm 0.01$ & 0.252 & & \\
\hline AII100-1 & 100 & $2388.8 \pm 0.01$ & 0.261 & & \\
\hline AII100-2 & 100 & $2443.7 \pm 0.01$ & 0.267 & 0.252 & -7.35 \\
\hline AII100-3 & 100 & $2086.8 \pm 0.01$ & 0.228 & & \\
\hline AII200-1 & 200 & $2198.8 \pm 0.01$ & 0.234 & & \\
\hline AII200-2 & 200 & $2071.7 \pm 0.01$ & 0.245 & 0.229 & -15.81 \\
\hline AII200-3 & 200 & $1730.5 \pm 0.01$ & 0.208 & & \\
\hline AII300-1 & 300 & $1986.1 \pm 0.01$ & 0.217 & & \\
\hline AII300-2 & 300 & $2095.9 \pm 0.01$ & 0.229 & 0.215 & -20.96 \\
\hline AII300-3 & 300 & $1821.3 \pm 0.01$ & 0.199 & & \\
\hline
\end{tabular}

TABle 6: Mode II fracture toughness of Type B mudstone specimens for different soaking times.

\begin{tabular}{|c|c|c|c|c|c|}
\hline \multirow[t]{2}{*}{ Specimen number } & \multirow[t]{2}{*}{ Soaking time $t$ (minutes) } & \multirow[t]{2}{*}{ Peak load $P_{\text {cr }}(\mathrm{N})$} & \multicolumn{2}{|c|}{$\begin{array}{l}\text { Mode II fracture toughness } \\
K_{\text {IIc }}\left(\mathrm{MPa} \mathrm{m}^{0.5}\right)\end{array}$} & \multirow[t]{2}{*}{ Degradation degree $D_{i t}(\%)$} \\
\hline & & & Test value & Average value & \\
\hline BII0-1 & 0 & $2301.4 \pm 0.01$ & 0.251 & & \\
\hline BII0-2 & 0 & $2011.5 \pm 0.01$ & 0.222 & 0.269 & 0 \\
\hline BII0-3 & 0 & $3047.4 \pm 0.01$ & 0.334 & & \\
\hline BII50-1 & 50 & $2196.6 \pm 0.01$ & 0.240 & & \\
\hline BII50-2 & 50 & $2084.8 \pm 0.01$ & 0.228 & 0.255 & -5.21 \\
\hline BII50-3 & 50 & $2719.2 \pm 0.01$ & 0.297 & & \\
\hline BII100-1 & 100 & $2394.8 \pm 0.01$ & 0.261 & & \\
\hline BII100-2 & 100 & $1812.2 \pm 0.01$ & 0.199 & 0.224 & -16.73 \\
\hline BII100-3 & 100 & $1947.0 \pm 0.01$ & 0.212 & & \\
\hline BII200-1 & 200 & $2180.5 \pm 0.01$ & 0.238 & & \\
\hline BII200-2 & 200 & $2304.5 \pm 0.01$ & 0.243 & 0.203 & -24.54 \\
\hline BII200-3 & 200 & $1177.5 \pm 0.01$ & 0.128 & & \\
\hline BII300-1 & 300 & $1885.4 \pm 0.01$ & 0.206 & & \\
\hline BII300-2 & 300 & $1912.9 \pm 0.01$ & 0.209 & 0.191 & -29.00 \\
\hline BII300-3 & 300 & $1446.1 \pm 0.01$ & 0.158 & & \\
\hline
\end{tabular}

TABle 7: Mode II fracture toughness of Type C mudstone specimens for different soaking times.

\begin{tabular}{|c|c|c|c|c|c|}
\hline \multirow[t]{2}{*}{ Specimen number } & \multirow[t]{2}{*}{ Soaking time $t$ (minutes) } & \multirow[t]{2}{*}{ Peak load $P_{\text {cr }}(\mathrm{N})$} & \multicolumn{2}{|c|}{$\begin{array}{l}\text { Mode II fracture toughness } \\
K_{\mathrm{IIc}}\left(\mathrm{MPa} \mathrm{m}{ }^{0.5}\right)\end{array}$} & \multirow[t]{2}{*}{ Degradation degree $D_{i t}(\%)$} \\
\hline & & & Test value & Average value & \\
\hline CII0-1 & 0 & $2489.5 \pm 0.01$ & 0.272 & & \\
\hline CII0-2 & 0 & $2297.3 \pm 0.01$ & 0.251 & 0.255 & 0 \\
\hline CII0-3 & 0 & $2214.9 \pm 0.01$ & 0.242 & & \\
\hline CII50-1 & 50 & $2452.8 \pm 0.01$ & 0.268 & & \\
\hline CII50-2 & 50 & $2150.8 \pm 0.01$ & 0.235 & 0.247 & -3.14 \\
\hline CII50-3 & 50 & $2178.3 \pm 0.01$ & 0.238 & & \\
\hline CII100-1 & 100 & $2022.7 \pm 0.01$ & 0.221 & & \\
\hline CII100-2 & 100 & $2077.6 \pm 0.01$ & 0.227 & 0.209 & -18.04 \\
\hline CII100-3 & 100 & $1638.3 \pm 0.01$ & 0.179 & & \\
\hline CII200-1 & 200 & $1583.4 \pm 0.01$ & 0.173 & & \\
\hline CII200-2 & 200 & $1290.5 \pm 0.01$ & 0.141 & 0.150 & -41.18 \\
\hline CII200-3 & 200 & $1244.7 \pm 0.01$ & 0.136 & & \\
\hline CII300-1 & 300 & $1052.5 \pm 0.01$ & 0.115 & & \\
\hline CII300-2 & 300 & $1080.0 \pm 0.01$ & 0.118 & 0.109 & -57.25 \\
\hline CII300-3 & 300 & $860.3 \pm 0.01$ & 0.094 & & \\
\hline
\end{tabular}




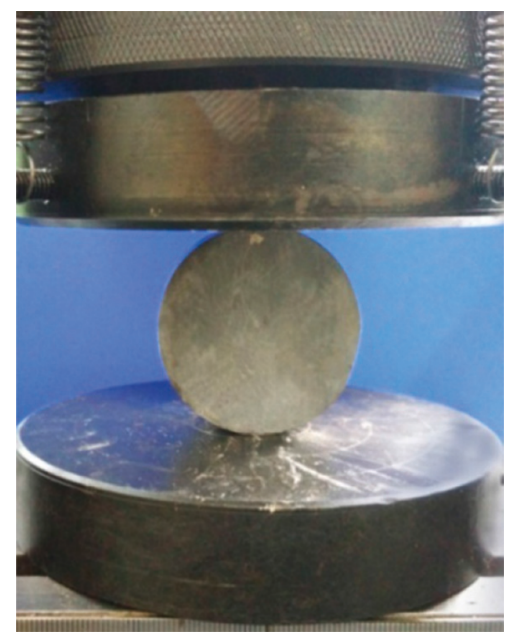

(a)

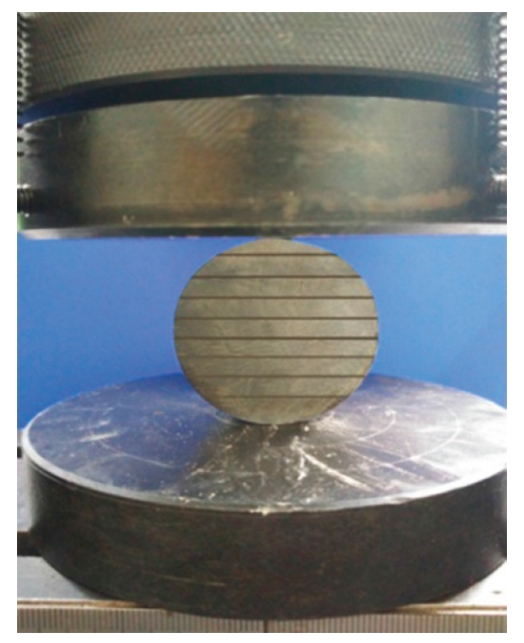

(b)

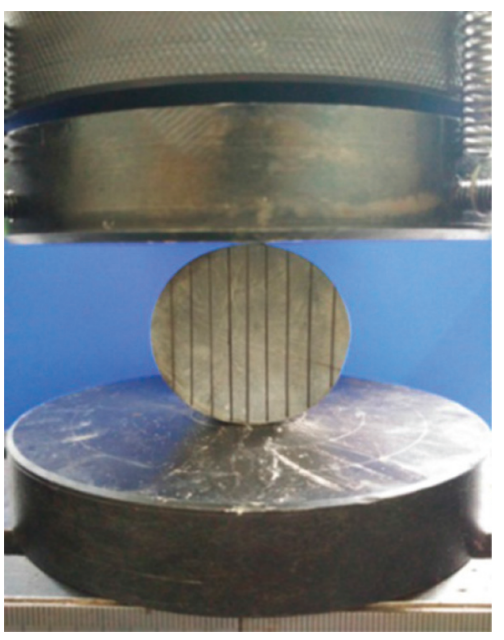

(c)

Figure 6: The tensile strength of (a) Type A, (b) Type B, and (c) Type C specimens measured by Brazilian disc test.

$\sigma_{\theta \theta}$ at a certain distance $r_{\mathrm{c}}$ along the direction defined by $\theta_{\mathrm{m}}$ is above the critical stress $\sigma_{\theta \theta c}$. The stresses near the crack tip depend on the $K_{\mathrm{I}}$ and $K_{\mathrm{II}}$. The traditional MTS criterion is given by

$$
\sigma_{\theta \theta c}=\frac{1}{\sqrt{2 \pi r_{\mathrm{c}}}} \cos ^{2} \frac{\theta_{\mathrm{m}}}{2}\left[K_{\mathrm{I}} \cos \frac{\theta_{\mathrm{m}}}{2}-3 K_{\mathrm{II}} \sin \frac{\theta_{\mathrm{m}}}{2}\right] .
$$

According to conventional and modified MTS criteria developed by Smith et al. [40] considers the $T$-stress which is a nonsingular and constant stress term and depends on the sample shape and loading conditions. T-stress has been calculated by Ayatollahi et al. [41] through finite element method, which is expressed for SCB specimens using the dimensionless parameter $T^{*}$ [29]:

$$
T=\frac{P}{2 R B} T^{*}\left(\frac{\alpha}{R}, \frac{S}{R}, \beta\right) .
$$

The dimensionless parameters $T^{*}$ hinges on the geometric parameters $S / R, \alpha / R$, and $\beta$. Ayatollahi and Aliha [27] demonstrated in detail that the modified MTS criterion could determine mode II fracture toughness using SCB specimens. Fracture toughness ratio $K_{\text {IIc }} / K_{\text {Ic }}$ is obtained as follows:

$$
\frac{K_{\mathrm{IIc}}}{K_{\mathrm{Ic}}}=\left[\sqrt{2 \pi r_{\mathrm{c}}} \frac{T}{K_{\mathrm{IIc}}} \sin ^{2} \theta_{\mathrm{m}}-\frac{3}{2} \cos \frac{\theta_{\mathrm{m}}}{2} \sin \theta_{\mathrm{m}}\right]^{-1} .
$$

According to equations (2) and (6), $T / K_{\text {IIc }}$ can be simplified as

$$
\frac{T}{K_{\text {IIc }}}=\frac{T^{*}}{Y_{\text {II }} \sqrt{\pi \alpha}}=\frac{T^{* *}}{\sqrt{\pi \alpha}} .
$$

Dimensionless parameters $T^{*}$ and $Y_{\text {II }}$ are obtained by the finite element method [29]. In this test, $T^{* *}$ is 4.678 , corresponding to the geometrical parameter $\alpha / R$ being 0.35 and $S / R$ being 0.5 . Finally, equation (7) is rewritten as

$$
\frac{K_{\mathrm{IIc}}}{K_{\mathrm{Ic}}}=\left[T^{* *} \sqrt{\frac{2 r_{\mathrm{c}}}{\alpha}} \sin ^{2} \theta_{\mathrm{m}}-\frac{3}{2} \cos \frac{\theta_{\mathrm{m}}}{2} \sin \theta_{\mathrm{m}}\right]^{-1},
$$

where $r_{\mathrm{c}}$ is a constant material parameter independent from specimen geometry. The critical distance $r_{\mathrm{c}}$ in rocks is defined as fracture process zone (FPZ) [42] in front of crack tip and is created in rocks because of microcrack initiation and coalescence by increasing the applied load. FPZ size in rock is estimated by maximum principal stress model suggested by Schmidt [43]:

$$
r_{\mathrm{c}}=\frac{1}{2 \pi}\left(\frac{K_{\mathrm{Ic}}}{\sigma_{\mathrm{t}}}\right)^{2}
$$

where $K_{\mathrm{Ic}}$ is mode I fracture toughness of mudstone and $\sigma_{\mathrm{t}}$ is rock tensile strength. In this test, three types of disc mudstone specimens, corresponding to the three types of the mudstone SCB specimens soaking for the same time, are used to calculate $\sigma_{\mathrm{t}}$ by the Brazilian test [44], as shown in Figure 6. The rock tensile strength and calculated $r_{\mathrm{c}}$ values for the mudstone are summarized in Table 8 .

In this test, the crack angle $\beta$ of the SCB specimen is taken as $54^{\circ}$ to calculate the pure mode II fracture toughness. Figure 7 depicts crack-growth trajectory of several typical SCB specimens with different degrees of damage under mode II loading. The Type A specimens AII0-1, AII50-1, AII100-1, AII200-1, and AII300-1 were separately immersed in water for $0,50,100,200$, and 300 minutes, respectively, and the other two types of specimens were exposed to the same soaking times as these Type A specimens. In the initial and low degree of damage stages, a distinct macrocrack starts at the crack tip up to axis loading location. With increasing soaking time, small cracks appear on the surface of the specimens, and the macrocrack initiation deviates gradually from the crack tip. The bedding structure of the mudstone influences the crack propagation, and the effect becomes stronger with the deepening degree of damage, particularly for the Type $\mathrm{C}$ specimens. With increasing soaking time, the 
TABLE 8: The tensile strength and the fracture process zone of the three types of mudstone specimens.

\begin{tabular}{|c|c|c|c|c|}
\hline Specimen type $(\mathrm{A}, \mathrm{B}, \mathrm{C})$ & $t$ (mins) & $K_{\mathrm{Ic}}\left(\mathrm{MPa} \mathrm{m}^{0.5}\right)$ & $\sigma_{\mathrm{t}}(\mathrm{MPa})$ & $r_{\mathrm{c}}(\mathrm{mm})$ \\
\hline \multirow{5}{*}{$\begin{array}{l}P \\
P\end{array}$} & 0 & 4.895 & $4.895 \pm 10^{-4}$ & 4.80 \\
\hline & 50 & 4.639 & $4.618 \pm 10^{-4}$ & 4.54 \\
\hline & 100 & 4.352 & $4.304 \pm 10^{-4}$ & 4.09 \\
\hline & 200 & 3.915 & $3.995 \pm 10^{-4}$ & 3.65 \\
\hline & 300 & 3.557 & $3.803 \pm 10^{-4}$ & 3.15 \\
\hline
\end{tabular}

Type A

$\begin{array}{lllll} & \\ & 0 & 0.820 & 4.626 \pm 10^{-4} & \\ \\ 1\end{array}$

Type B

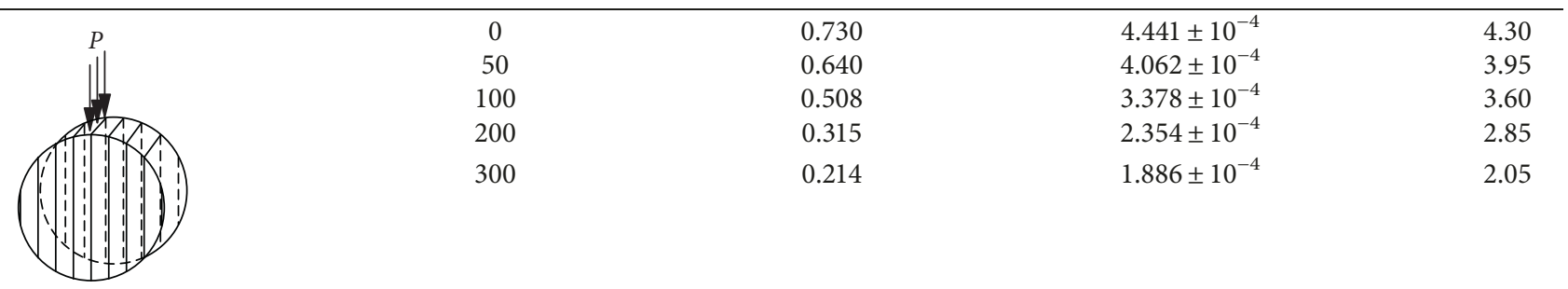

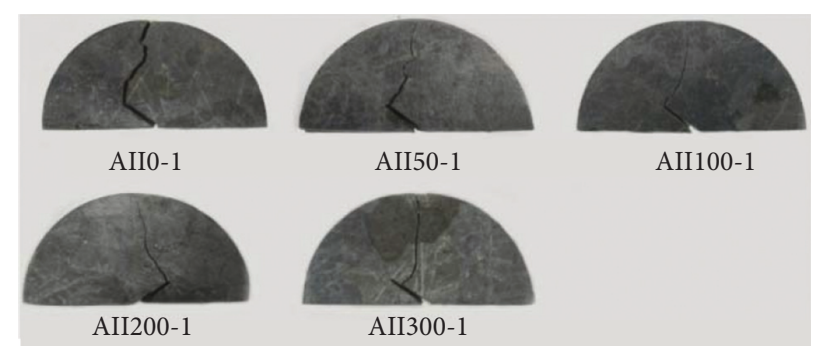

(a)

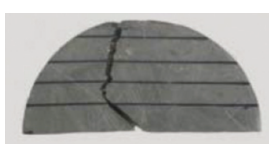

BII0-1

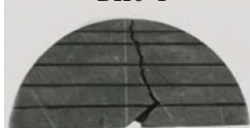

BII200-1

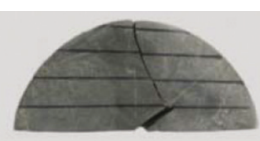

BII50-1

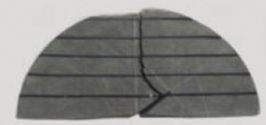

BII300-1

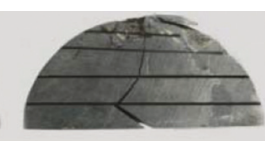

BII100-1

(b)

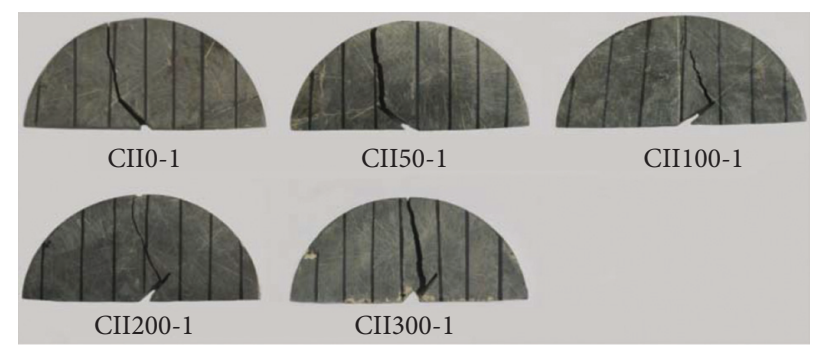

(c)

FIgUre 7: The propagation of crack in (a) Type A, (b) Type B, and (c) Type C SCB specimens for pure mode II with different degrees of damage. 


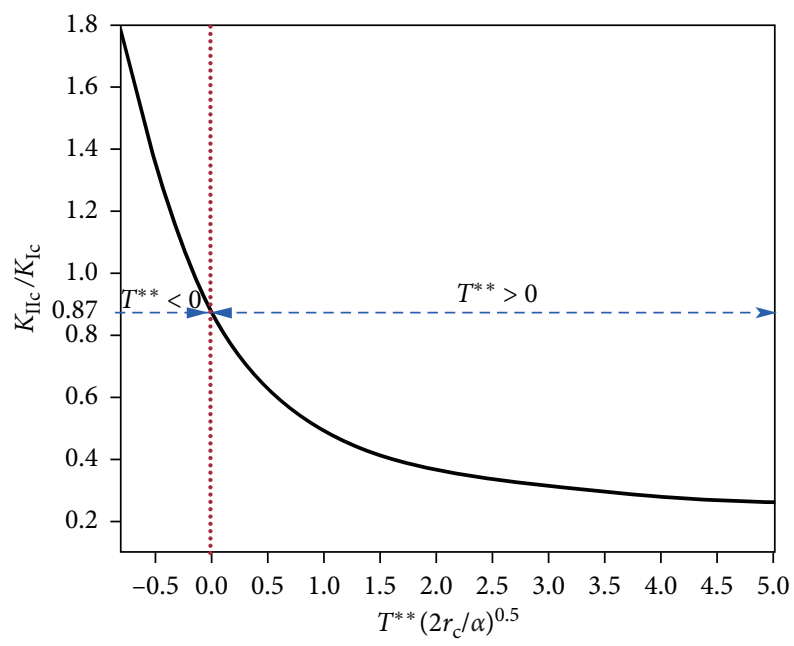

FIGURE 8: The fracture toughness ratio $K_{\text {IIc }} / K_{\text {Ic }}$ of SCB specimen according to modified MTS criterion.

crack propagation path of the Type C specimens overlaps with the direction of the weakened bedding. The crack spreading trends of the three types of specimens under mixed-mode I/II loadings are identical to mode II.

Based on the conventional MTS criterion, fracture toughness ratio $K_{\text {IIc }} / K_{\text {Ic }}$ constantly equals 0.87 . Nevertheless, this test ratio is, in reality, smaller than 0.87 . According to equation (9), the fracture toughness ratio $K_{\text {IIc }} / K_{\text {Ic }}$ is obtained in terms of $T^{* *} \sqrt{2 r_{\mathrm{c}} / \alpha}$ using modified MTS criterion. Figure 8 shows the plot of relevant numerical results, and mode II fracture toughness is decreased as $T^{* *} \sqrt{2 r_{c} / \alpha}$ increases.

Figures 9(a)-9(c), corresponding to the three types of the specimens, compares $K_{\text {IIc }}$ to $K_{\text {Ic }}$ ratio achieved from test results with theoretical values obtained from modified MTS criterion. In the initial stage, when the degree of damage is low, the curve of the experimental results is in accordance with the theoretical curve. However, after soaking Types A, B, and $\mathrm{C}$ specimens for 300 minutes, test curves and theoretical curves clearly deviate. With increasing soaking time, the ratio of $K_{\text {IIc }}$ to $K_{\text {Ic }}$ increases. In addition, the test results of the Type $B$ specimens have less consistency with the theoretical values than the other two types of specimens. The bedding has an effect on mudstone mode II fracture toughness.

3.4. Mixed-Mode I/II Fracture Toughness of Mudstones. We also measured mixed-mode I/II fracture toughness of three mudstone specimens with different degrees of water damage. The mixed-mode equivalent intensity factor $K_{\text {eff }}$ and the mixity parameter $M^{e}$ are [38]

$$
\begin{aligned}
K_{\mathrm{eff}} & =\sqrt{K_{\mathrm{Im}}^{2}+K_{\mathrm{IIm}}^{2}}, \\
M^{e} & =\frac{1}{2 \pi} \tan ^{-1}\left(\frac{K_{\mathrm{Im}}}{K_{\mathrm{IIm}}}\right),
\end{aligned}
$$

where the $K_{\mathrm{Im}}\left(K_{\mathrm{IIm}}\right)$ is mode I (II) stress intensity factor. $M^{e}$ value is 1 and 0 for pure modes I and II, respectively.
According to equation (5), considering $T$-stress and ignoring higher order terms of $O\left(r^{1 / 2}\right)$, mixed-mode fracture toughness ratio $K_{\text {eff }} / K_{\text {Ic }}$ is determined by Ayatollahi and Aliha [34] as

$$
\begin{aligned}
\frac{K_{\mathrm{eff}}}{K_{\mathrm{Ic}}}= & {\left[\cos ^{2} \frac{\theta_{\mathrm{m}}}{2}\left(\frac{K_{\mathrm{Im}}}{K_{\mathrm{eff}}} \cos \frac{\theta_{\mathrm{m}}}{2}-3 \frac{K_{\text {IIm }}}{K_{\mathrm{eff}}} \sin \frac{\theta_{\mathrm{m}}}{2}\right)\right.} \\
& \left.+\frac{T \sqrt{2 \pi r_{\mathrm{c}}}}{K_{\mathrm{eff}}} \sin ^{2} \theta_{\mathrm{m}}\right]^{-1},
\end{aligned}
$$

where $r_{\mathrm{c}}$ is the fracture progress zone of the three types of SCB specimens with different soaking times (refer to Table 8). By substituting equations (1), (2), and (6) into equations (12) and (13), the mixture parameter $M^{e}$ and mixed-mode fracture toughness ratio $K_{\text {eff }} / K_{\text {Ic }}$ are achieved for SCB specimens in terms of $Y_{\mathrm{I}}, Y_{\mathrm{II}}$, and $T^{*}$ as follows:

$$
\begin{aligned}
M^{e}= & \frac{2}{\pi} \tan ^{-1}\left(\frac{Y_{\mathrm{I}}}{Y_{\mathrm{II}}}\right), \\
\frac{K_{\mathrm{eff}}}{K_{\mathrm{Ic}}}= & \sqrt{Y_{\mathrm{I}}^{2}+Y_{\mathrm{II}}^{2}}\left[\cos ^{2} \frac{\theta_{\mathrm{m}}}{2}\left(Y_{\mathrm{I}} \cos \frac{\theta_{\mathrm{m}}}{2}-3 Y_{\mathrm{II}} \sin \frac{\theta_{\mathrm{m}}}{2}\right)\right. \\
& \left.+T^{*} \sqrt{\frac{2 r_{\mathrm{c}}}{\alpha}} \sin ^{2} \theta_{\mathrm{m}}\right]^{-1} .
\end{aligned}
$$

Through finite element analyses, Ayatollahi and Aliha [34] obtained the nondimensional parameters $Y_{\mathrm{I}}, Y_{\mathrm{II}}$, and $T^{*}$ of SCB specimens under various crack inclination angles $(\beta)$. Based on equation (14), the mixity parameter $M^{e}$ can be obtained and is shown in Table 1.

Each type of mudstone SCB specimens includes four groups of mixed I/II fracture toughness experiments corresponding to 4 crack inclination angles $\left(5^{\circ}, 15^{\circ}, 30^{\circ}\right.$, and $45^{\circ}$ ) under varying degrees of water damage. There are at least three effective sets of experimental data for each experimental condition. Figure 10 describes the mixed I/II 


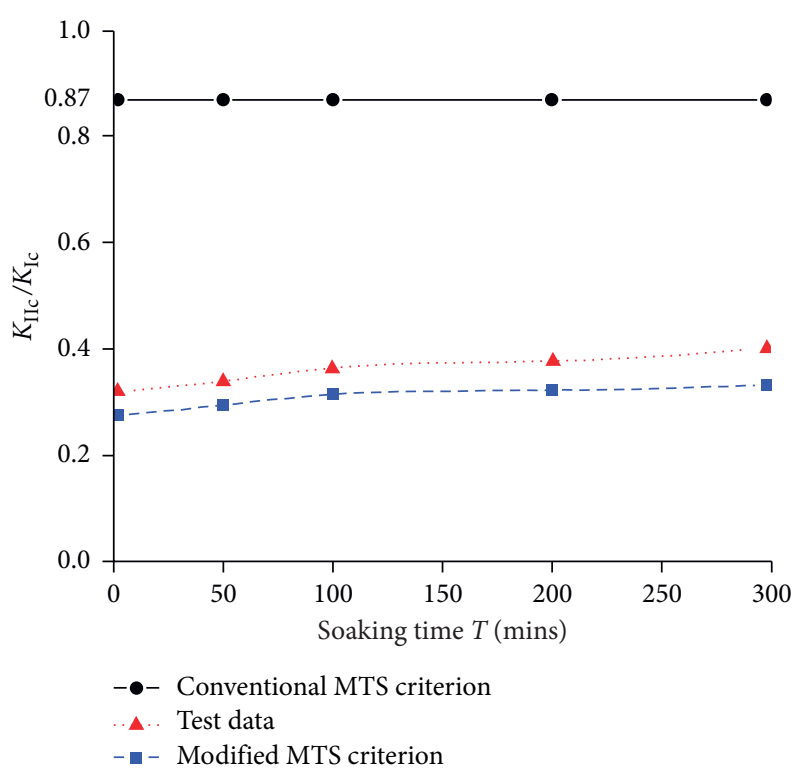

(a)

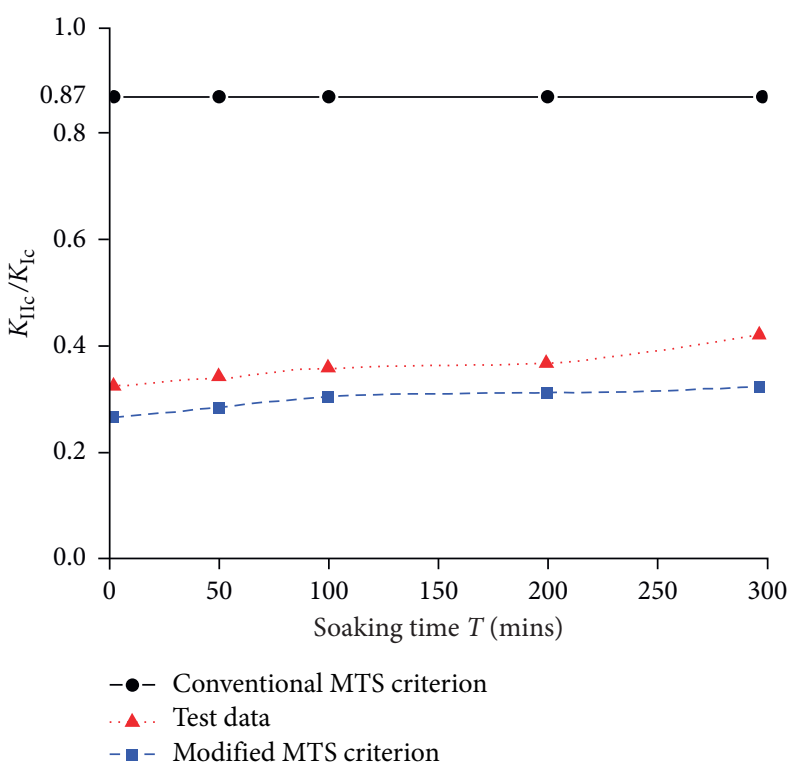

(b)

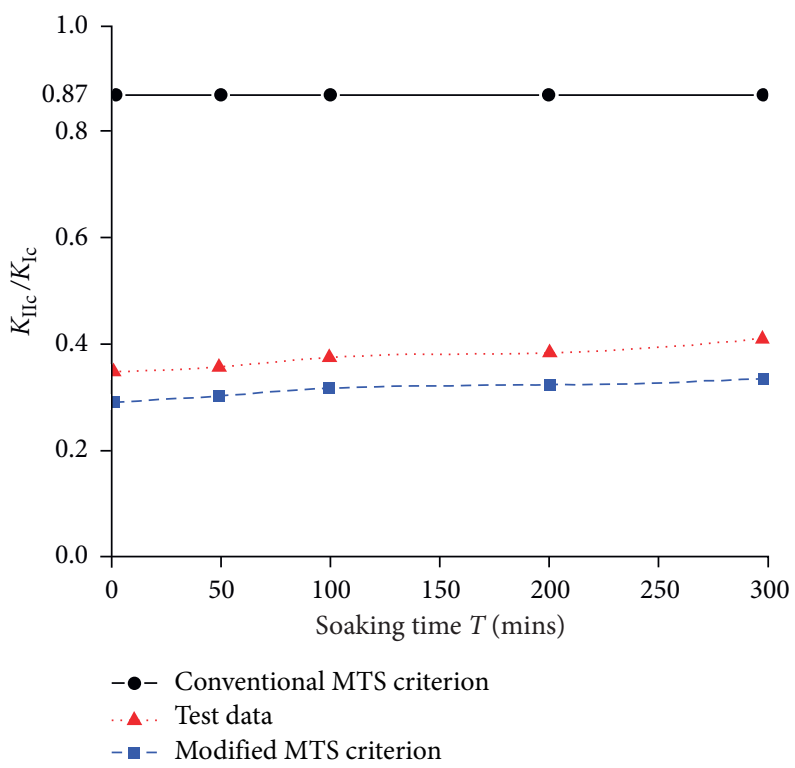

(c)

FIgURE 9: Comparison of test ratio $K_{\text {IIc }} / K_{\text {Ic }}$ of three types of the mudstone SCB specimens with theoretical values according to the modified MTS criterion: (a) Type A, (b) Type B, and (c) Type C specimens for soaking 0, 50, 100, 200, and 300 minutes.

fracture toughness $K_{\mathrm{eff}} / K_{\mathrm{Ic}}$ of mudstone SCB specimens with different soaking duration by the modified MTS criterion. Figure 10 shows a curve fitted to the average of the test data employing least-squares technique. In the noand low-damage stages, the experimental ratio of $K_{\text {eff }}$ to $K_{\text {Ic }}$ is in good compliance with theoretical predictions through modified MTS criterion. With increasing soaking time, the degree of damage deepens, and microcracks arise inside the mudstone specimens. In addition, the bedding has a relatively large effect on mixed-mode I/II fracture toughness. Test data curve is gradually deviated from theoretical curve. When soaking time reaches 300 minutes for the three types of specimens, these deviations become easily detectable. By comparing the ratio $K_{\text {eff }} / K_{\text {Ic }}$ for the three types of mudstone SCB specimens, the test data for the Type A specimens is observed to provide better compliance with theoretical predictions by modified MTS criterion than those for the other two types of specimens because the SCB specimens are simplified as a plane stress model and because the Type A specimens are regarded as an isotropic material in which the influence of bedding is disregarded to a certain extent. 

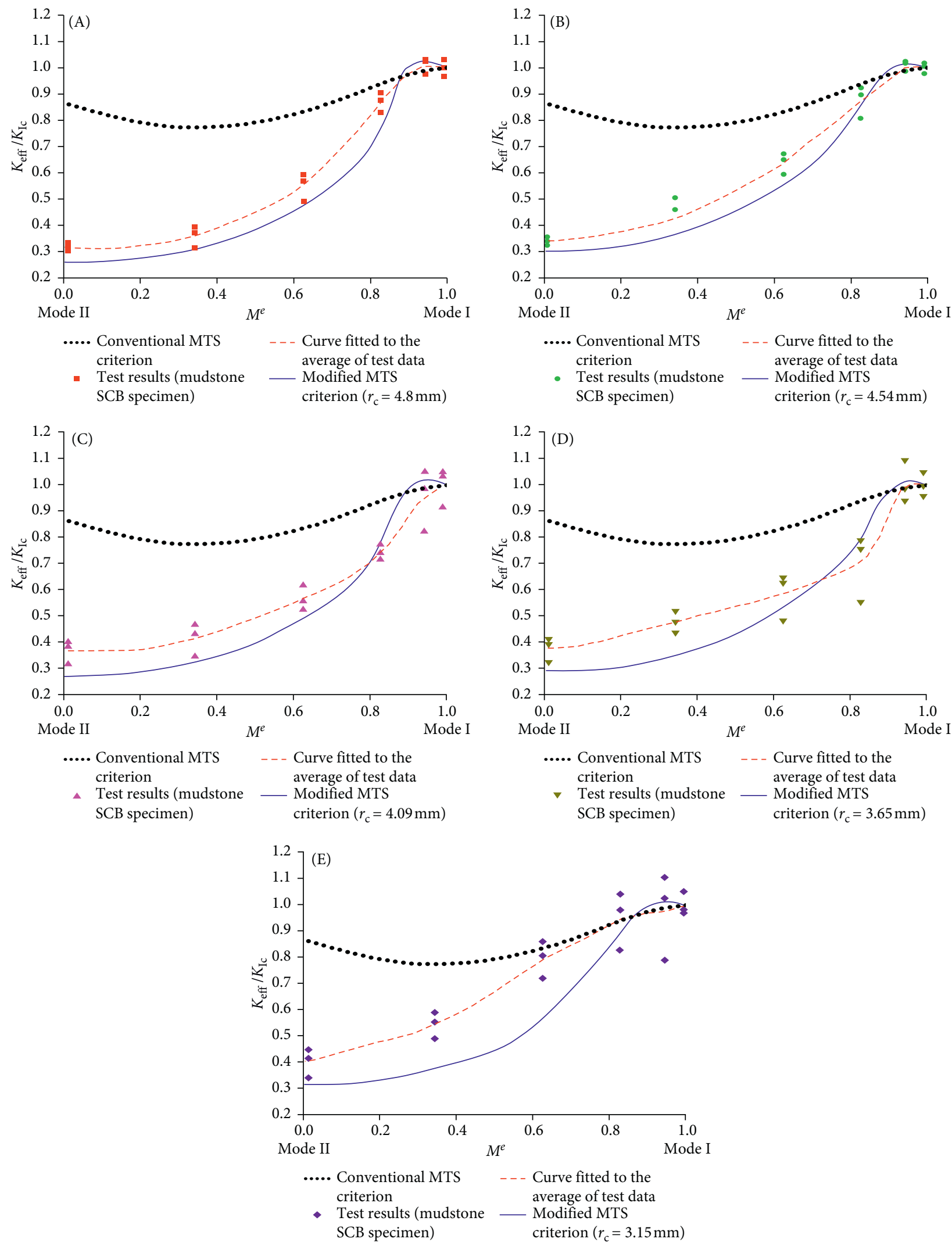

(a)

Figure 10: Continued. 

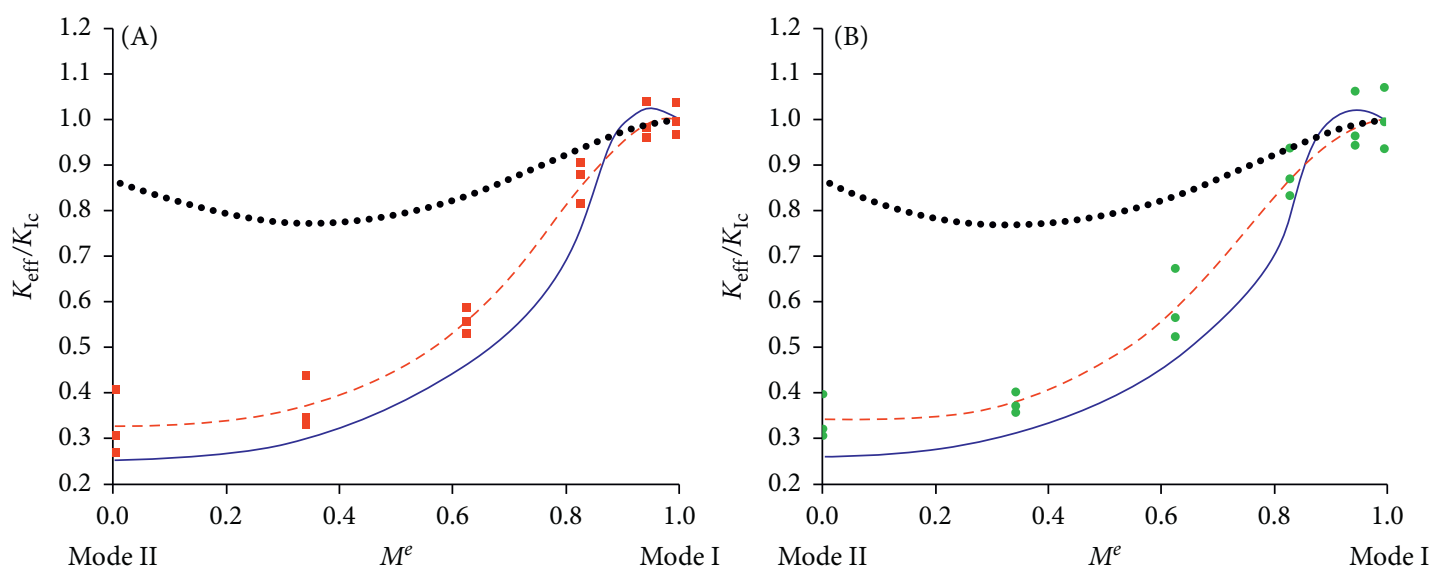

.... Conventional MTS -. Curve fitted to the criterion average of test data

- Test results (mudstone — Modified MTS SCB specimen) criterion $\left(r_{\mathrm{c}}=5.0 \mathrm{~mm}\right)$

.... Conventional MTS - - Curve fitted to the criterion average of test data

- Test results (mudstone — Modified MTS SCB specimen) criterion $\left(r_{\mathrm{c}}=4.75 \mathrm{~mm}\right)$
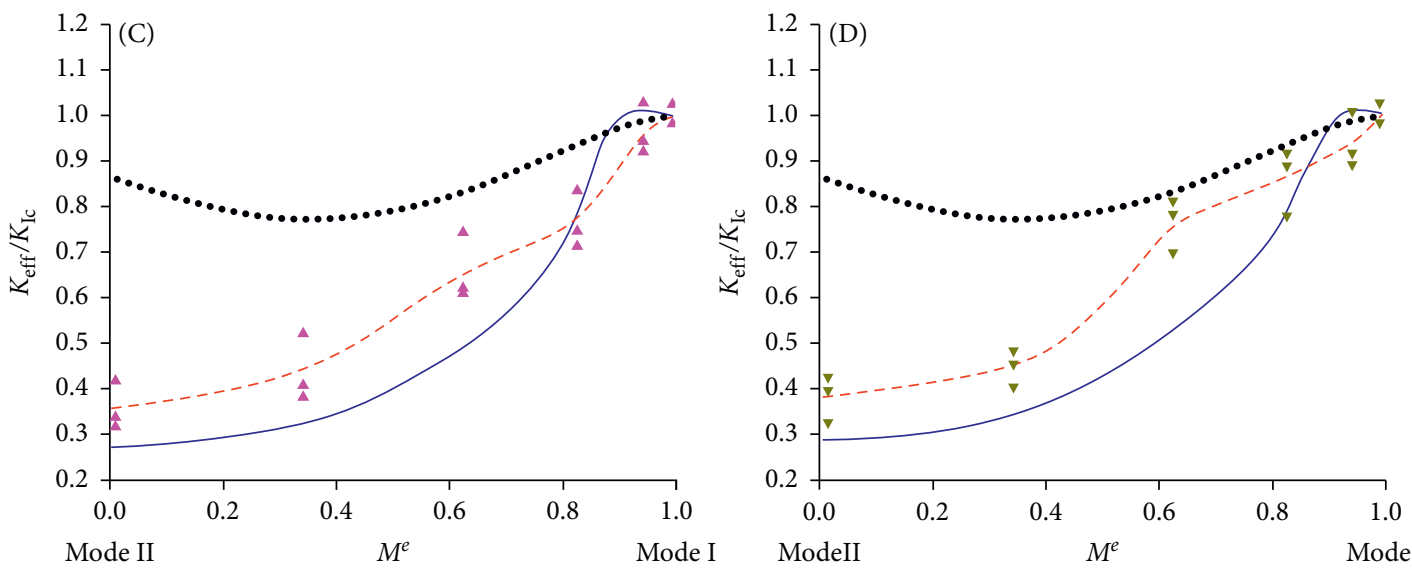
Mode II ... Conventional MTS $\quad$-. Curve fitted to the criterion average of test data

A Test results (mudstone — Modified MTS SCB specimen) Modified MTS
criterion $\left(r_{\mathrm{c}}=4.47 \mathrm{~mm}\right)$

ModeI $M^{e}$

... Conventional MTS $\quad-$ Curve fitted to the criterion average of test data

- Test results (mudstone — Modified MTS SCB specimen) criterion $\left(r_{\mathrm{c}}=4.05 \mathrm{~mm}\right)$

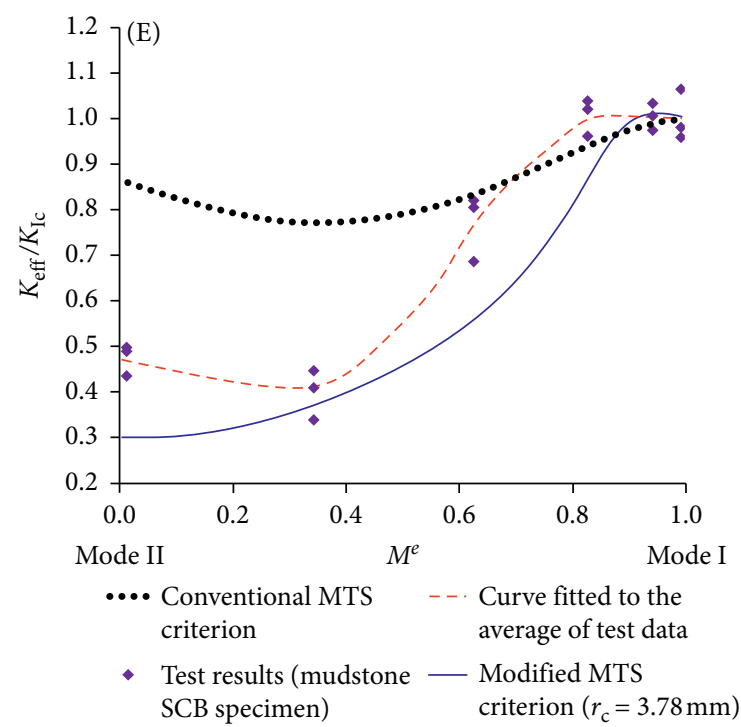

(b)

Figure 10: Continued. 

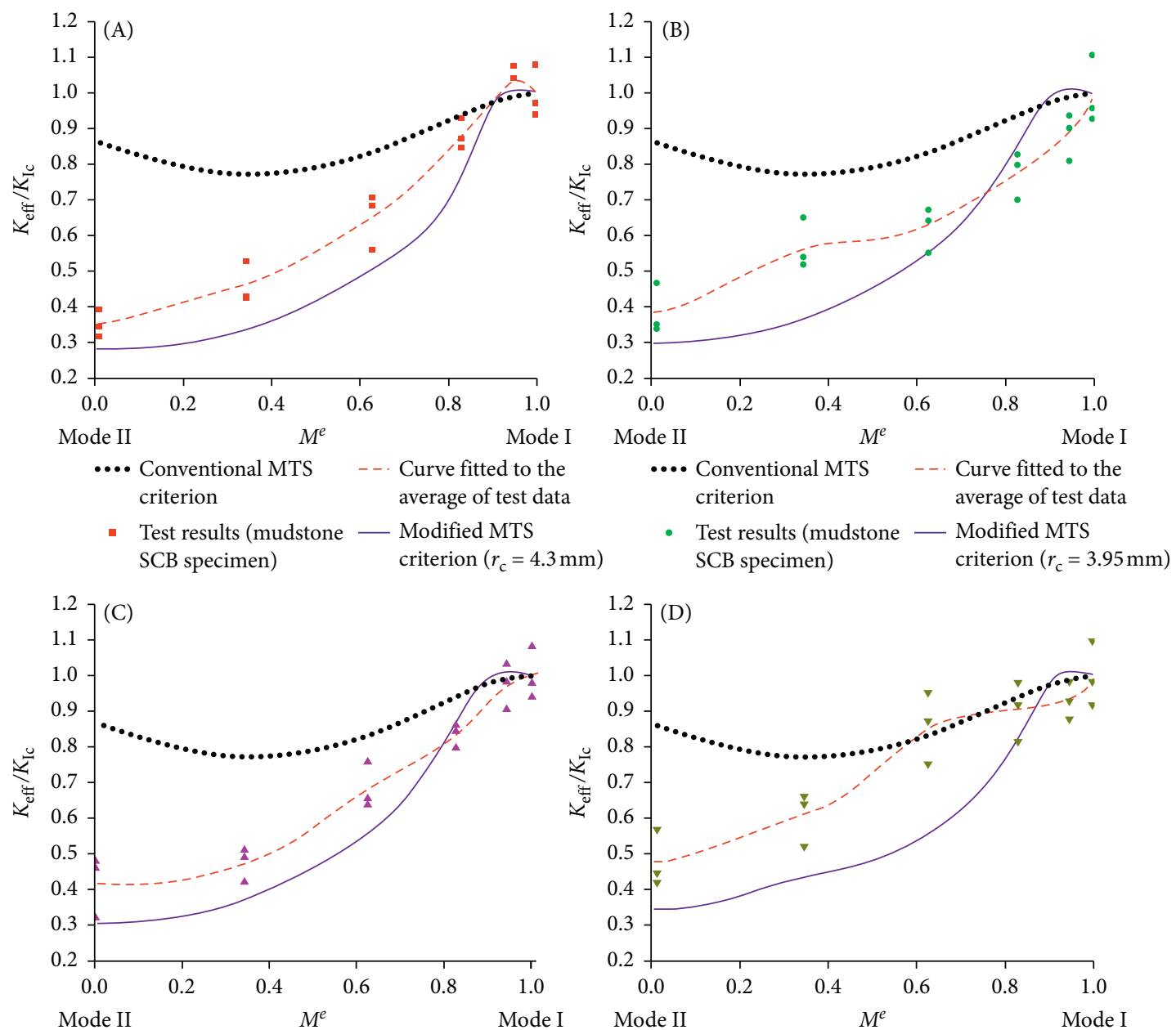

.... Conventional MTS - - . Curve fitted to the criterion average of test data

- Test results (mudstone — Modified MTS SCB specimen) Modified MTS
criterion $\left(r_{\mathrm{c}}=3.6 \mathrm{~mm}\right)$

•... Conventional MTS _ - - Curve fitted to the criterion average of test data

$\checkmark$ Test results (mudstone — Modified MTS SCB specimen) criterion $\left(r_{\mathrm{c}}=2.85 \mathrm{~mm}\right)$

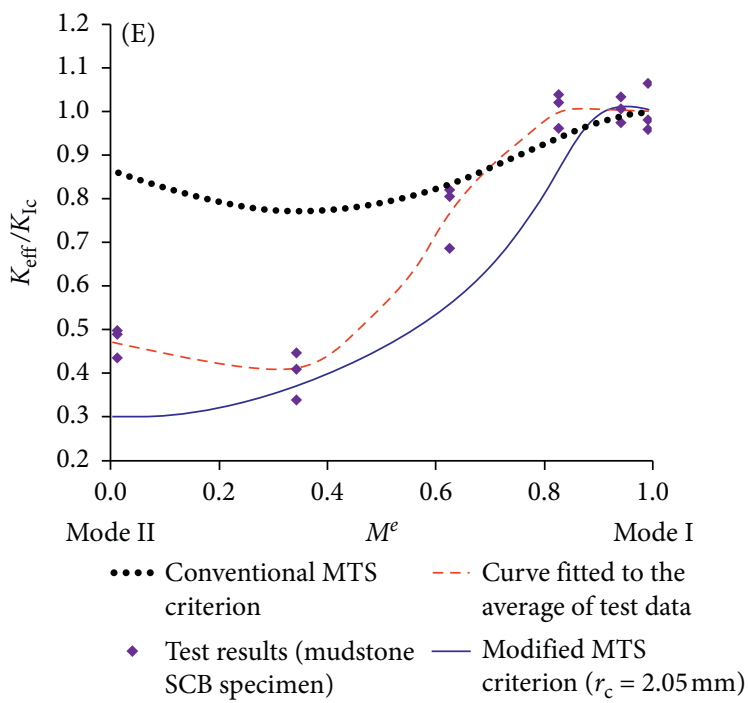

(c)

FIGURE 10: Comparison of $K_{\mathrm{eff}} / K_{\mathrm{Ic}}$ test ratio of the three types of the mudstone SCB specimens with theoretical values by modified MTS criterion. (a) Type A, (b) Type B, and (c) Type C specimens for soaking 0 (A), 50 (B), 100 (C), 200 (D), and 300 (E) minutes. 


\section{Conclusions}

In this test, the effects of water on the fracture toughness of mudstones in pure modes I and II and mix mode I/II with bedding are investigated using three types of SCB specimens. Theoretical results and experimental findings according to the modified MTS criterion are compared here. The following conclusions are drawn in this work:

(1) This test used a special coring method to obtain native mudstone SCB specimens, which are classified into three types corresponding to the three bedding directions. The fracture toughness of Type A (divider configuration) specimens has the largest value for all tested modes and same soaking time and that of the Type C (transverse configuration) specimens is considerably smaller than the other two types.

(2) With increasing soaking time, fracture toughness for all tested modes and for all three types of mudstone specimens decreases, and failure characteristics are changed from being brittle to being ductile. In particular, the degree of degradation of the Type C specimens is higher than that of the other types for each soaking time period.

(3) The degree of degradation of pure mode I fracture toughness is slightly higher than pure mode II, proving that the water sensitivity of pure mode I fracture toughness is higher. $K_{\mathrm{IIC}} / K_{\text {Ic }}$ ratio increases when the soaking time is extended. In the initial and short soaking time stages, the experimental $K_{\text {IId }} / K_{\text {Ic }}$ values are consistent with theoretical findings according to modified MTS criterion. However, after being soaked 300 minutes, the test curves deviate from the theoretical curves.

(4) Based on the modified MTS criterion, mixed-mode I/II ratio of $K_{\text {eff }}$ to $K_{\text {Ic }}$ is consistent with the theoretical values for a low degree of water damage. With soaking time increasing, test data curve is gradually deviated from the theoretical curve. When soaking time reaches 300 minutes for the three types of specimens, the deviation is substantial. The test data characterizing the Type A specimens are in better agreement with the theoretical prediction than the other two specimen types.

\section{Data Availability}

Data supporting this research article are available from the corresponding author.

\section{Conflicts of Interest}

The authors declare that they have no conflicts of interest.

\section{Acknowledgments}

The authors acknowledge the support by the National Natural Science Foundation for Young Scientists of China (grant no. 51904202) and China Scholarship Council (201703780108).

\section{References}

[1] M. R. Vergara and T. Triantafyllidis, "Influence of water content on the mechanical properties of an argillaceous swelling rock," Rock Mechanics and Rock Engineering, vol. 49, no. 2, pp. 2555-2568, 2016.

[2] G. C. Li, C. C. Qi, Y. T. Sun, X. L. Tang, and B. Q. Hou, "Experimental study on the softening characteristics of sandstone and mudstone in relation to moisture content," Shock and Vibration, vol. 2017, Article ID 4010376, 14 pages, 2017.

[3] F. Valès, D. Nguyen Minh, H. Gharbi, and A. Rejeb, "Experimental study of the influence of the degree of saturation on physical and mechanical properties in Tournemire shale (France)," Applied Clay Science, vol. 26, no. 1-4, pp. 197-207, 2004.

[4] Q. T. Pham, F. Vales, L. Malinsky, D. Nguyen Minh, and H. Gharbi, "Effects of desaturation-resaturation on mudstone," Physics and Chemistry of the Earth, Parts $A / B / C$, vol. 32, no. 8-14, pp. 646-655, 2007.

[5] Z. A. Erguler and R. Ulusay, "Water-induced variations in mechanical properties of clay-bearing rocks," International Journal of Rock Mechanics and Mining Sciences, vol. 46, no. 2, pp. 355-370, 2009.

[6] T. P. Gautam and A. Shakoor, "Slaking behavior of claybearing rocks during a one-year exposure to natural climatic conditions," Engineering Geology, vol. 166, pp. 17-25, 2013.

[7] H. Karakul and R. Ulusay, "Empirical correlations for predicting strength properties of rocks from P-wave velocity under different degrees of saturation," Rock Mechanics and Rock Engineering, vol. 46, no. 5, pp. 981-999, 2013.

[8] G. R. Irwin, "Analysis of stresses and strains near the end of a crack transversing a plate," Journal of Applied MechanicsTransactions of the ASME, vol. 24, pp. 361-364, 1957.

[9] J. F. Yang, W. G. Liang, Y. D. Chen, L. Li, and H. J. Lian, "Experiment research on the fracturing characteristics of mudstone with different degrees of water damage," Chinese Journal Rock Mechanics and Engineering, vol. 36, pp. 95-104, 2017.

[10] J. Yang, H. Lian, W. Liang, V. P. Nguyen, and Y. Chen, "Experimental investigation of the effects of supercritical carbon dioxide on fracture toughness of bituminous coals," International Journal of Rock Mechanics and Mining Sciences, vol. 107, pp. 233-242, 2018.

[11] J. Yang, H. Lian, W. Liang, V. P. Nguyen, and S. P. A. Bordas, "Model I cohesive zone models of different rank coals," International Journal of Rock Mechanics and Mining Sciences, vol. 115, pp. 145-156, 2019.

[12] R. Q. Huang, L. Z. Wu, and B. Li, "Crack initiation criteria and fracture simulation for precracked sandstones," Advances in Materials Science and Engineering, vol. 2019, Article ID 9359410, 12 pages, 2019.

[13] C. M. Haberfield and I. W. Johnston, "Determination of the fracture toughness of a saturated soft rock," Canadian Geotechnical Journal, vol. 27, no. 3, pp. 276-284, 1990.

[14] I. L. Lim, I. W. Johnston, S. K. Choi, and J. N. Boland, "Fracture testing of a soft rock with semi-circular specimens under three-point bending. Part 1-mode I," International Journal of Rock Mechanics and Mining Sciences \& Geomechanics Abstracts, vol. 31, no. 3, pp. 185-197, 1994. 
[15] C.-H. Chen, C.-S. Chen, and J.-H. Wu, "Fracture toughness analysis on cracked ring disks of anisotropic rock," Rock Mechanics and Rock Engineering, vol. 41, no. 4, pp. 539-562, 2008.

[16] P. F. Wu, W. G. Liang, Z. G. Li, M. T. Cao, and J. F. Yang, "Investigations on mechanical properties and crack propagation characteristics of coal and sandy mudstone using three experimental methods," Rock Mechanics and Rock Engineering, vol. 50, no. 1, pp. 215-223, 2017.

[17] T. M. Maccagno and J. F. Knott, "The fracture behaviour of PMMA in mixed modes I and II," Engineering Fracture Mechanics, vol. 34, no. 1, pp. 65-86, 1989.

[18] M. Y. He, H. C. Cao, and A. G. Evans, "Mixed-mode fracture: the four-point shear specimen," Acta Metallurgica et Materialia, vol. 38, no. 5, pp. 839-846, 1990.

[19] M. D. Kuruppu, Y. Obara, M. R. Ayatollahi, K. P. Chong, and T. Funatsu, "ISRM-suggested method for determining the mode I static fracture toughness using semi-circular bend specimen," Rock Mechanics and Rock Engineering, vol. 47, no. 1, pp. 267-274, 2014.

[20] H. Q. Lin, G. Y. Lin, B. Ganesh, and D. K. Shetty, "Investigation of the compact-tension-shear (CTS) specimen by the method of caustics," International Journal of Fracture, vol. 88, pp. 47-52, 1997.

[21] C. Xu and R. J. Fowell, "Stress intensity factor evaluation for cracked chevron notched Brazilian disc specimens," International Journal of Rock Mechanics and Mining Sciences \& Geomechanics Abstracts, vol. 31, no. 2, pp. 157-162, 1994.

[22] F. Dai, Y. Xu, T. Zhao, N.-W. Xu, and Y. Liu, "Loading-ratedependent progressive fracturing of cracked chevron-notched Brazilian disc specimens in split Hopkinson pressure bar tests," International Journal of Rock Mechanics and Mining Sciences, vol. 88, pp. 49-60, 2016.

[23] K. Chong and M. D. Kuruppu, "New specimen for fracture toughness determination for rock and other materials," International Journal of Fracture, vol. 26, pp. 59-62, 1984.

[24] K. P. Chong, M. D. Kuruppu, and J. S. Kuszmaul, "Fracture toughness determination of layered materials," Engineering Fracture Mechanics, vol. 28, no. 1, pp. 43-54, 1987.

[25] K. P. Chong and M. D. Kuruppu, "New specimens for mixed mode fracture investigations of geomaterials," Engineering Fracture Mechanics, vol. 30, no. 5, pp. 701-712, 1988.

[26] I. L. Lim, I. W. Johnston, and S. K. Choi, "Stress intensity factors for semi-circular specimens under three-point bending," Engineering Fracture Mechanics, vol. 44, no. 3, pp. 363-382, 1993.

[27] M. R. Ayatollahi and M. R. M. Aliha, "On determination of mode II fracture toughness using semi-circular bend specimen," International Journal of Solids and Structures, vol. 43, no. 17 , pp. 5217-5227, 2006.

[28] M. R. Ayatollahi, M. R. M. Aliha, and M. M. Hassani, "Mixed mode brittle fracture in PMMA-An experimental study using SCB specimens," Materials Science and Engineering: A, vol. 417, no. 1-2, pp. 348-356, 2006.

[29] M. R. Ayatollahi and M. R. M. Aliha, "Fracture parameters for a cracked semi-circular specimen," International Journal of Rock Mechanics and Mining Sciences, vol. 41, pp. 20-25, 2004.

[30] J.-J. Wang, J.-G. Zhu, C. F. Chiu, and H. Zhang, "Experimental study on fracture toughness and tensile strength of a clay," Engineering Geology, vol. 94, no. 1-2, pp. 65-75, 2007.

[31] I. L. Lim, I. W. Johnston, S. K. Choi, and J. N. Boland, "Fracture testing of a soft rock with semi-circular specimens under three-point bending. Part 2-mixed-mode,"
International Journal of Rock Mechanics and Mining Sciences \& Geomechanics Abstracts, vol. 31, no. 3, pp. 199-212, 1994.

[32] K. Khan and N. A. Al-Shayea, "Effect of specimen geometry and testing method on mixed mode I-II fracture toughness of a limestone rock from Saudi Arabia," Rock Mechanics and Rock Engineering, vol. 33, no. 3, pp. 179-206, 2000.

[33] M. R. Ayatollahi and M. R. M. Aliha, "Wide range data for crack tip parameters in two disc-type specimens under mixed mode loading," Computational Materials Science, vol. 38, no. 4, pp. 660-670, 2007.

[34] M. R. Ayatollahi and M. R. M. Aliha, "Fracture toughness study for a brittle rock subjected to mixed mode I/II loading," International Journal of Rock Mechanics and Mining Sciences, vol. 44, no. 4, pp. 617-624, 2007.

[35] H. Huang and P. Che, "Research on micro-mechanism of softening and argillitization of mudstone," Journal Tongji University, vol. 35, no. 7, p. 866, 2007.

[36] Q. Lyu, X. Long, P. G. Ranjith, J. Tan, and Y. Kang, "Experimental investigation on the mechanical behaviours of a low-clay shale under water-based fluids," Engineering Geology, vol. 233, pp. 124-138, 2018.

[37] G. C. Sih, "Strain-energy-density factor applied to mixed mode crack problems," International Journal of Fracture, vol. 10, no. 3, pp. 305-321, 1974.

[38] M. A. Hussain, S. L. Pu, and J. Underwood, "Strain energy release rate for a crack under combined mode I and mode II," in Proceedings of the Fracture Analysis: Proceedings of the 1973 National Symposium on Fracture Mechanics, Part II, ASTM International, College Park, MD, USA, August 1973.

[39] F. Erdogan and G. C. Sih, "On the crack extension in plates under plane loading and transverse shear," Journal of Basic Engineering, vol. 85, no. 4, pp. 519-525, 1963.

[40] D. J. Smith, M. R. Ayatollahi, and M. J. Pavier, "The role of T-stress in brittle fracture for linear elastic materials under mixed-mode loading," Fatigue Fracture of Engineering Materials and Structures, vol. 24, no. 2, pp. 137-150, 2001.

[41] M. R. Ayatollahi, M. J. Pavier, and D. J. Smith, "Determination of T-stress from finite element analysis for mode I and mixed mode I/II loading," International Journal of Fracture, vol. 91, no. 3, pp. 283-298, 1998.

[42] J. F. Labuz, S. P. Shah, and C. H. Dowding, "The fracture process zone in granite: evidence and effect," International Journal of Rock Mechanics and Mining Sciences \& Geomechanics Abstracts, vol. 24, no. 4, pp. 235-246, 1987.

[43] R. A. Schmidt, "A microcrack model and its significance to hydraulic fracturing and fracture toughness testing," in Proceedings of the 21st US Symposium on Rock Mechanics (USRMS), pp. 581-590, American Rock Mechanics Association, Rolla, MO, USA, May 1980.

[44] C. S. Chen, E. Pan, and B. Amadei, "Determination of deformability and tensile strength of anisotropic rock using Brazilian tests," International Journal of Rock Mechanics and Mining Sciences, vol. 35, no. 1, pp. 43-61, 1998. 


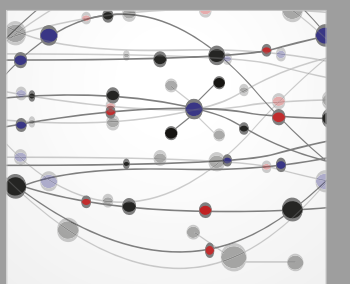

The Scientific World Journal
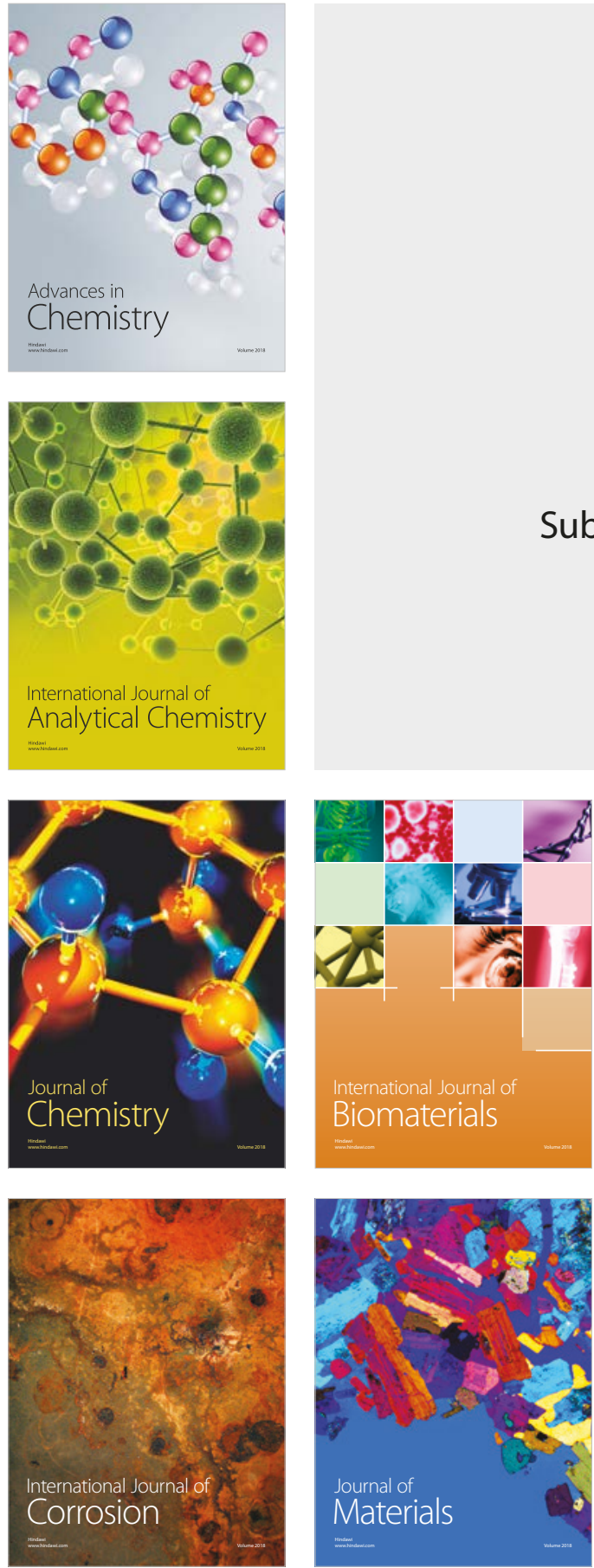

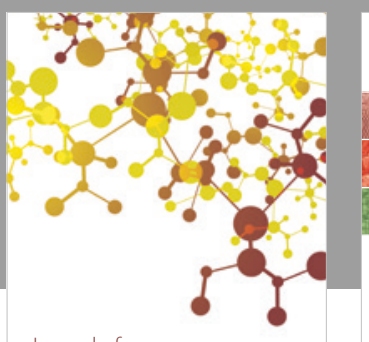

Journal of

Applied Chemistry
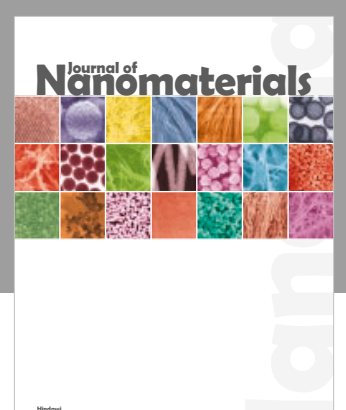

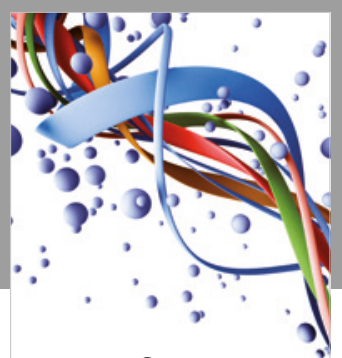

Scientifica

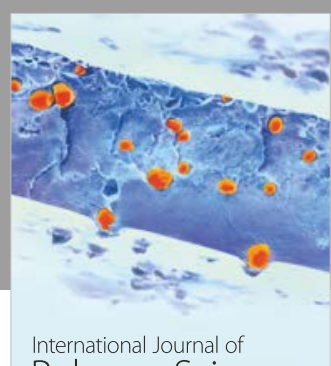

Polymer Science

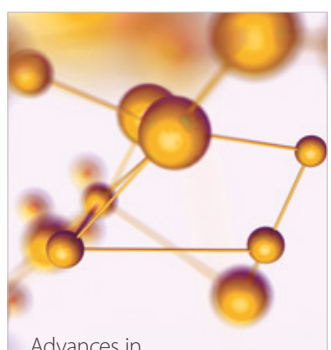

Physical Chemistry
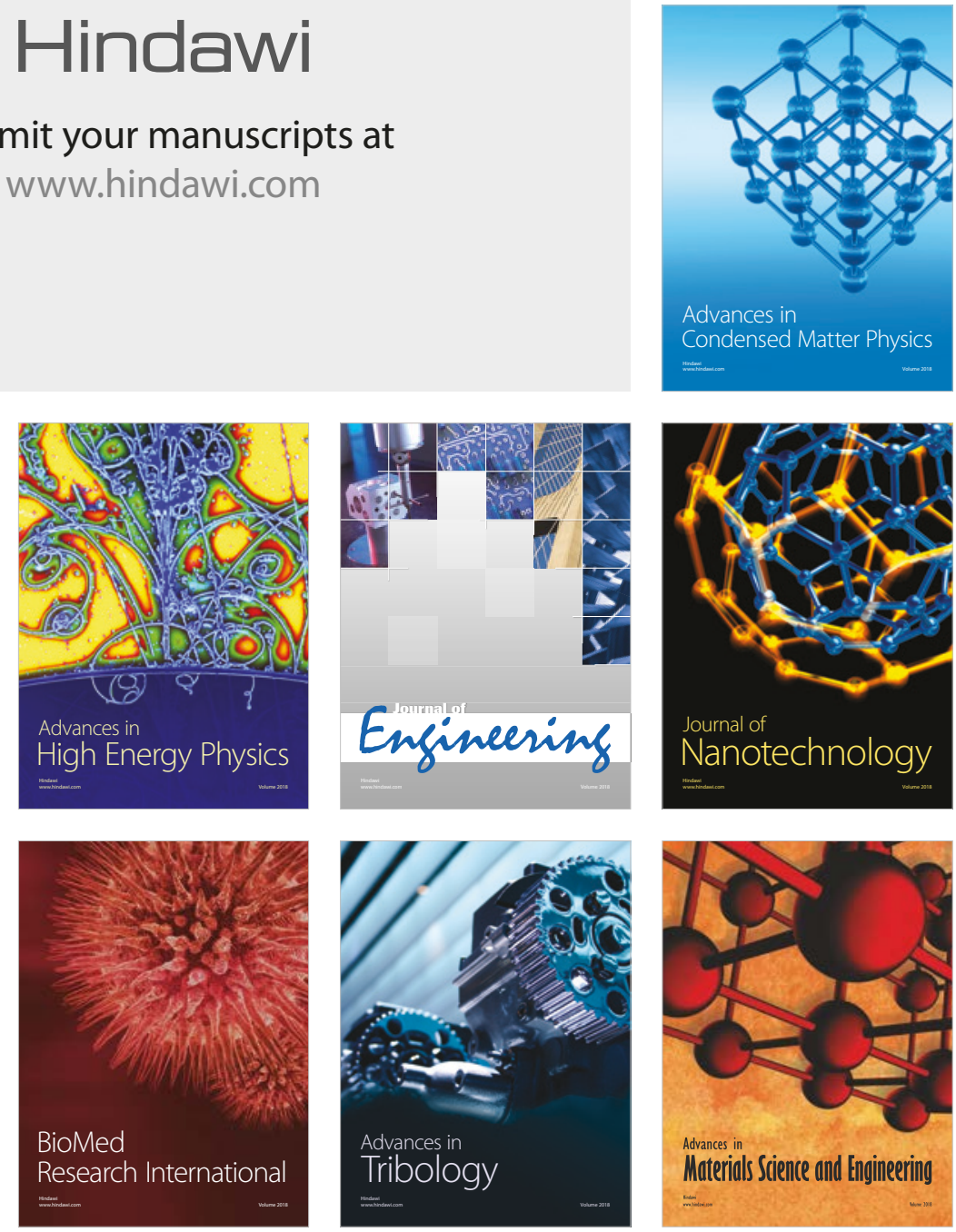